\title{
Post-Flight Aerodynamic and Aerothermal Model Validation of a Supersonic Inflatable Aerodynamic Decelerator
}

\author{
Chun Tang ${ }^{1}$ \\ NASA Ames Research Center, Moffett Field, CA 94035 \\ Suman Muppidi ${ }^{2}$ \\ ERC Inc., NASA Ames Research Center, Moffett Field, CA 94035 \\ Deepak Bose ${ }^{3}$ \\ NASA Ames Research Center, Moffett Field, CA 94035 \\ John W. Van Norman ${ }^{4}$ \\ AMA Inc., NASA Langley Research Center, Hampton, VA 23681 \\ Rebekah Tanimoto ${ }^{5}$ and Ian Clark ${ }^{6}$ \\ NASA Jet Propulsion Laboratory, Pasadena, CA 91109
}

\begin{abstract}
NASA's Low Density Supersonic Decelerator Program is developing new technologies that will enable the landing of heavier payloads in low density environments, such as Mars. A recent flight experiment conducted high above the Hawaiian Islands has demonstrated the performance of several decelerator technologies. In particular, the deployment of the Robotic class Supersonic Inflatable Aerodynamic Decelerator (SIAD-R) was highly successful, and valuable data were collected during the test flight. This paper outlines the Computational Fluid Dynamics (CFD) analysis used to estimate the aerodynamic and aerothermal characteristics of the SIAD-R. Pre-flight and post-flight predictions are compared with the flight data, and a very good agreement in aerodynamic force and moment coefficients is observed between the CFD solutions and the reconstructed flight data.
\end{abstract}

\section{Nomenclature}

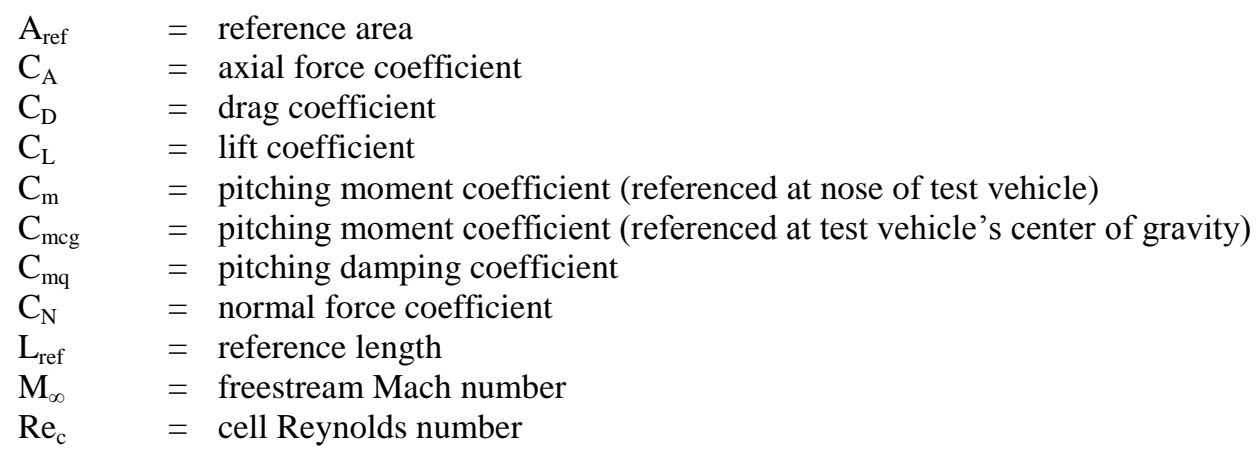

\footnotetext{
${ }^{1}$ Research Engineer, Senior Member AIAA

${ }^{2}$ Research Scientist, Senior Member AIAA

${ }^{3}$ Aerospace Engineer, Associate Fellow AIAA

${ }^{4}$ Senior Project Engineer, Member AIAA

${ }^{5}$ Propulsion Engineer, Member AIAA

${ }^{6}$ LDSD Principal Investigator, Member AIAA
} 


$\begin{array}{ll}\mathrm{T}_{\infty} & =\text { freestream temperature } \\ \mathrm{t} & =\text { time } \\ \mathrm{V}_{\infty} & =\text { freestream velocity } \\ \mathrm{V} & =\text { local velocity magnitude } \\ a & =\text { speed of sound } \\ \alpha & =\text { angle of attack } \\ \beta & =\text { angle of sideslip } \\ \rho_{\infty} & =\text { freestream density } \\ y_{+} & =\text {non-dimensional wall distance } \\ u^{*} & =\text { friction velocity } \\ v & =\text { local kinematic viscosity } \\ \Delta \eta & =\text { body normal distance }\end{array}$

\section{Introduction}

The objective of NASA's Low Density Supersonic Decelerator (LDSD) Program is to develop the next generation of decelerator technologies that will enable future space missions to land heavier payloads in a low density environment like Mars. On June 28, 2014, a Supersonic Flight Dynamics Test (SFDT-1) was conducted in the stratosphere over the Hawaiian Islands to study the performance of several decelerator technologies. Details of the SFDT-1 campaign and decelerator technologies are available in papers by Clark ${ }^{1}$ and Giersch ${ }^{2}$. One technology under development is an inflatable drag device designed for deployment at higher supersonic speeds that are currently beyond the reach of parachutes. This inflatable concept, known as the Robotic class Supersonic Inflatable

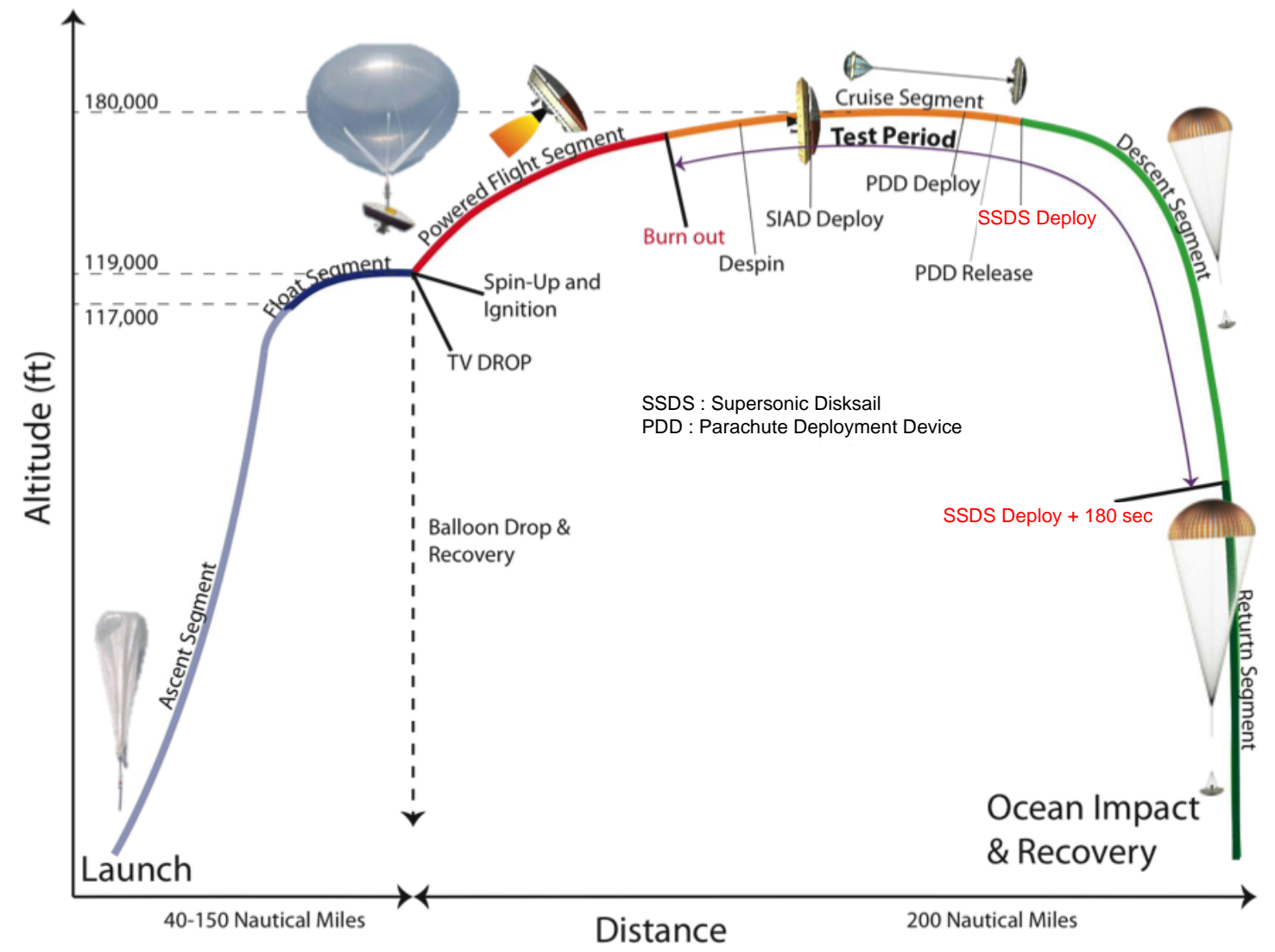

Figure 1. Nominal Timeline of Supersonic Flight Dynamics Test (SFDT)

American Institute of Aeronautics and Astronautics 
Aerodynamic Decelerator (SIAD-R), was successfully tested during SFDT-1 and valuable flight data were collected. Fig. 1 is a nominal timeline of the test flight. The actual deployment of SIAD-R occurred at a slightly higher altitude of $58.1 \mathrm{~km}(190,600 \mathrm{ft}$.) with inflation at approximately $\mathrm{t}=82.6 \mathrm{~s}$ after the balloon drop. The SIAD-R was fully inflated in less than $0.5 \mathrm{sec}$, and the test vehicle decelerated from a freestream Mach number of 4.06 to 2.73 in approximately 78 seconds.

The SIAD-R is stowed inside a $4.7 \mathrm{~m}$ diameter rigid aeroshell. When fully inflated, SIAD-R expands to a design diameter of $6 \mathrm{~m}$ (see Fig. 2). As illustrated in Fig. 3, the inflatable section of the vehicle consists of a torus region and a burble fence. The burble fence provides a uniform and pre-determined separation location, thereby increasing the aerodynamic stability of the design. The SIAD-R is intended to exhibit minimal shape changes while flying at supersonic speeds. This rigidity is achieved by inflating the SIAD-R to a high internal pressure ( $28 \mathrm{kPa})$ using onboard gas generators. Rocket sled testing ${ }^{2}$ of the SIAD-R design at relevant conditions showed that maximum surface deformations are on the order of $3 \mathrm{~cm}$. Since these shape changes are small when compared to the overall size of the test vehicle, it was assumed the vehicle behaved as a rigid body and aeroelastic effects were not considered in our numerical simulations. Outlined below are the Computational Fluid Dynamics (CFD) analyses used to estimate the aerodynamic and aerothermal environments of the SIAD-R during the supersonic cruise
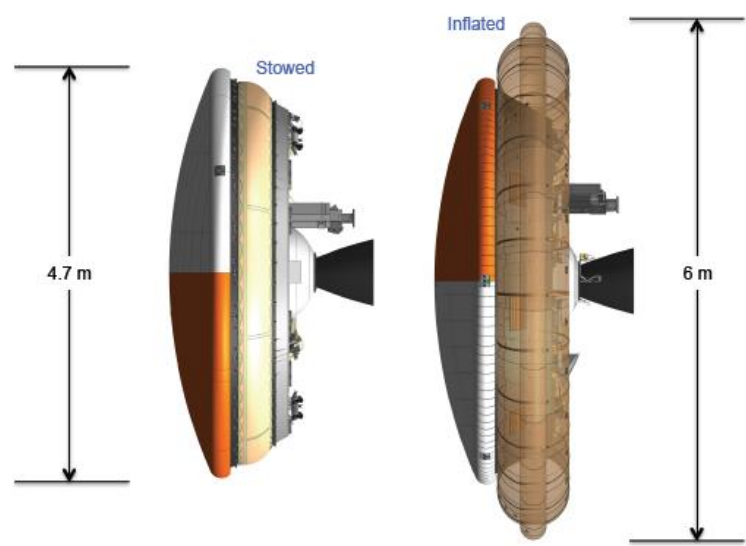

Figure 2. Schematic of SIAD-R in Stowed vs. Inflated Configuration.

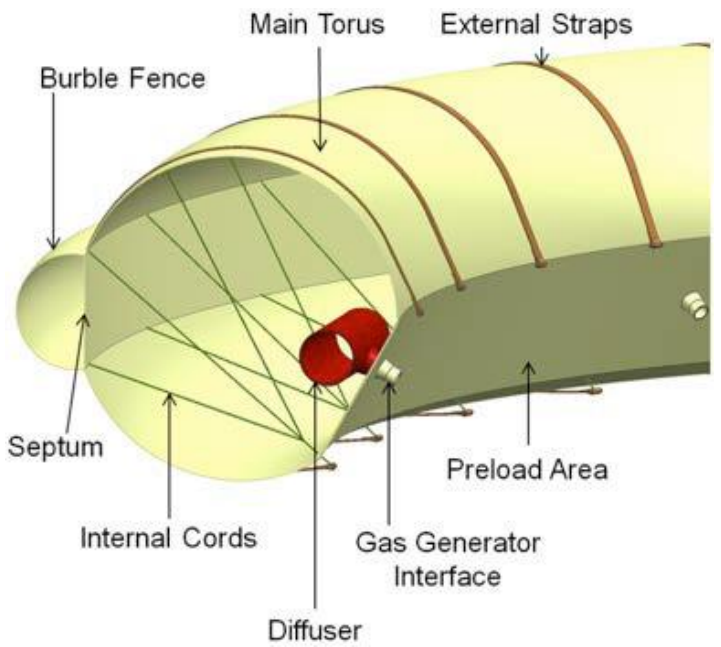

Figure 3. Details of SIAD-R Construction

segment of SFDT-1.

\section{Aerodynamics Analysis}

To estimate the aerodynamic characteristics of SIAD-R, a series of Computational Fluid Dynamics (CFD) simulations were computed using the Data Parallel Line Relaxation (DPLR) code $^{3}$, a fluid mechanics software package developed and maintained at NASA Ames Research Center. Numerical simulations were performed at relevant flight conditions: freestream Mach numbers ranging from 2 to 4; altitudes of $41 \mathrm{~km}, 47 \mathrm{~km}$, and $60 \mathrm{~km}$; and angles of attack from $0^{\circ}$ to $90^{\circ}$. The flow was modeled as a perfect gas, and constant wall temperatures from $300 \mathrm{~K}$ to $500 \mathrm{~K}$ (expected temperature range on SIAD-R's surface) were applied at the wall boundaries. Both laminar and turbulent simulations were computed to predict the aerodynamic performance of the SIAD-R at supersonic cruise conditions; turbulent flow computations employed an SST turbulence model ${ }^{4}$.

\section{A. Sensitivity of Geometry Modeling}

The inflatable section of SIAD-R is constructed from 27 circumferential gores of silicone-coated Kevlar fabric. It also contains a number of external straps and internal cords (see Figure 3) to support the torus and burble fence when fully inflated. As illustrated in Fig. 4, the aftbody of the SFDT test vehicle holds various hardware elements, such as the STAR-48B motor, spin-up and spin-down motors, plume deflectors, Parachute Deployment Device (PDD), and video cameras. As a result of these design elements, the SIAD-R geometry is not a simple axisymmetric 


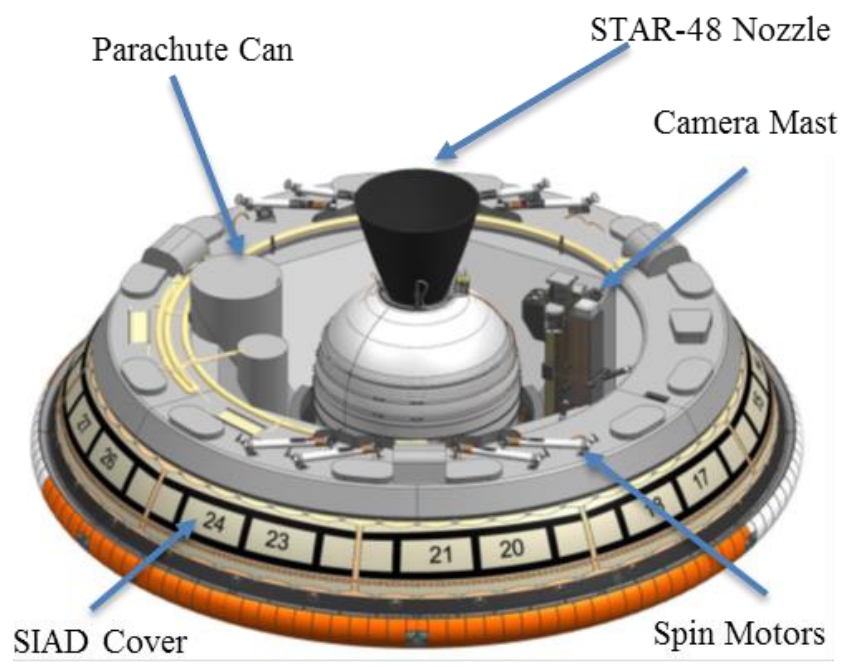

Figure 4. Isometric view of SFDT aftbody

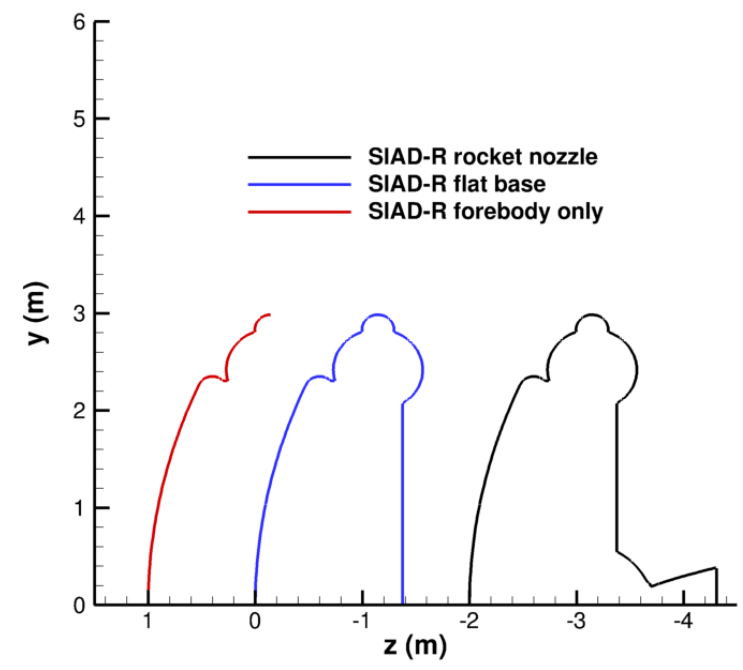

Figure 5. Comparison of axisymmetric geometries

body. While it is possible to model all the geometric features in the CFD simulations, these calculations are quite time-consuming and it is impractical to run the large number of cases necessary to produce an aerodynamic database (ADB). Instead, a sensitivity study was conducted to determine if the vehicle geometry could be simplified without altering the general aerodynamic characteristics of the SIAD-R.

\section{Axisymmetric Simulations}

In an effort to simplify the grid generation process and improve solution turnaround time, the first set of SIAD-R simulations consisted of modeling only the forebody geometry and assuming the vehicle to be axisymmetric. As illustrated by the red line in Figure 5, the forebody is defined by the rigid aeroshell and sections of the torus and bubble fence. The forebody geometry terminated at the maximum diameter of the burble fence. A hyperbolic grid containing 167 x 161 points was created using the Gridgen ${ }^{5}$ software tool, and DPLR was used to model the test vehicle at several altitudes, velocities, and wall temperatures. To estimate the aerodynamic drag over the entire vehicle, backshell corrections $^{6}$ from the Viking flight data were combined with the forebody values. As a comparison, axisymmetric full-body simulations with a simple flat backshell (shown as the blue line in Fig. 5) were also computed. A comparison of the drag coefficients between the two sets of simulations (forebody plus backshell corrections vs. full-body axisymmetric) at $\alpha=0^{\circ}$ showed good agreement. Based on these promising results, additional CFD simulations using these axisymmetric

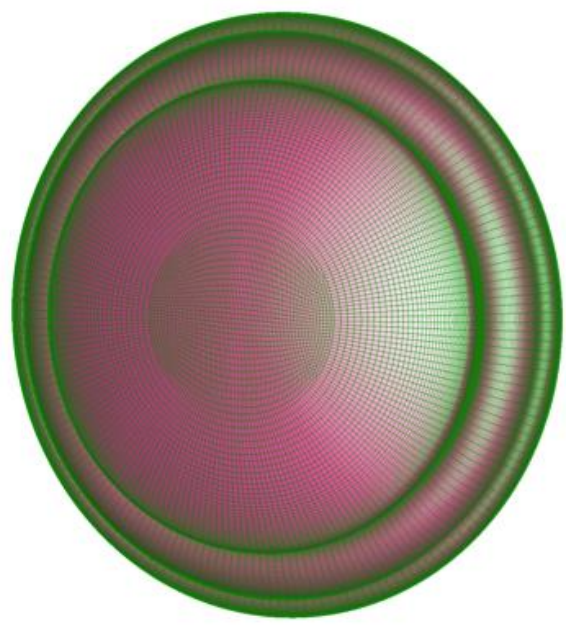

Figure 6. Axisymmetric surface grid shapes were performed at several angles of attack.

For comparison purposes, two freestream conditions were selected to span the expected upper and lower values of the Mach number. These flight relevant conditions (containing freestream velocity, Mach number, density, and temperature) are listed in Table 1.

\begin{tabular}{|c|c|c|c|}
\hline $\mathbf{V}_{\infty}(\mathbf{m} / \mathbf{s})$ & $\mathbf{M}_{\infty}$ & $\rho_{\infty}\left(\mathbf{g} / \mathbf{m}^{\mathbf{3}}\right)$ & $\mathbf{T}_{\infty}(\mathbf{K})$ \\
\hline 1309 & 3.97 & 1.466 & 270.5 \\
\hline 689.8 & 2.12 & 1.973 & 264 \\
\hline
\end{tabular}

Table 1. Reference freestream conditions for simulation comparisons 


\section{Three-dimensional Simulations}

To begin the three-dimensional computations, surface grids were created using the Gridgen program. Shown in Figure 6 is an example of the surface grid topology used in the fully-body axisymmetric mesh. Grid layers were extruded from the surface grid using a hyperbolic subroutine in Gridgen, and the resulting volume grid contained around 10 million mesh points. This baseline volume grid was used to simulate the SIAD-R at various angles of attack. To accurately resolve the shock in front of the test vehicle, the outer boundary of the volume grid was aligned with the bow shock using the built-in mesh alignment feature in DPLR. Shown in Figure 7 is an example of a shock-aligned grid and a close-up of the mesh near the surface of the SIAD-R. The surface wall spacing was also adjusted such that the cell Reynolds number $\left\{\operatorname{Re}_{\mathrm{c}}=(a+\mathrm{V}) \Delta \eta / v\right\}$ is approximately 1 everywhere on the surface. This clustering also result in a non-dimensional wall distance $\left(y^{+}=u^{*} y / v\right)$ of less than 1 , which is a recommended value for turbulent flow calculations.

Figure 8 shows a representative solution highlighting the pressure contours at the pitch plane and the averaged pressure profiles on the SIAD-R forebody. As expected, the surface pressure is highest at the stagnation point and decreases as the flow expands around the aeroshell. The flow separates from the rigid aeroshell and reattaches on the inflated torus section. At the impingement point, a local pressure peak is observed. The flow again separates ahead of the burble fence leading to another reattachment point on the burble fence and a second local peak in pressure. In general, the solutions were unsteady in the separated flow regions (especially in the wake region of the backshell), but the integrated forces and moments were relatively steady (values of $\mathrm{C}_{\mathrm{L}}, \mathrm{C}_{\mathrm{D}}$, and $\mathrm{C}_{\mathrm{m}}$ varied by less than $1 \%$ ). Shown in Figure 9 is the averaged pressure contours on the SIAD-R forebody at $\alpha=0^{\circ}, 10^{\circ}, 20^{\circ}$ for a freestream $\mathbf{M}_{\infty}=2.12$. As expected, the stagnation point shifts away from the apex as the angle of attack is increased. The pressures on the backshell are quite low at these supersonic conditions; therefore, changes in the aftbody geometry should have minimal effects on the overall aerodynamics.

To quantify the aerodynamic differences between full body calculations vs. forebody with base corrections, the lift, drag, and pitching moment coefficients are tabulated in Table 2. The force and moment coefficients are calculated using a reference length of $\mathrm{L}_{\text {ref }}=6.0 \mathrm{~m}$ and a reference area of $\mathrm{A}_{\mathrm{ref}}=28.27 \mathrm{~m}^{2}$. As evident from the table, discrepancies between the forebody+backshell correction vs. full-body results are relatively small, with maximum differences of less than $4 \%$ in the force and moment coefficients for the high $\alpha$ cases. It should be noted that the Viking backshell corrections did not account for angle of attack effects so this may be a possible source of the differences observed between the two solution sets. The discrepancy is higher at $\mathrm{M}_{\infty}=2.12$ probably because of a greater contribution of backshell pressure on vehicle drag.
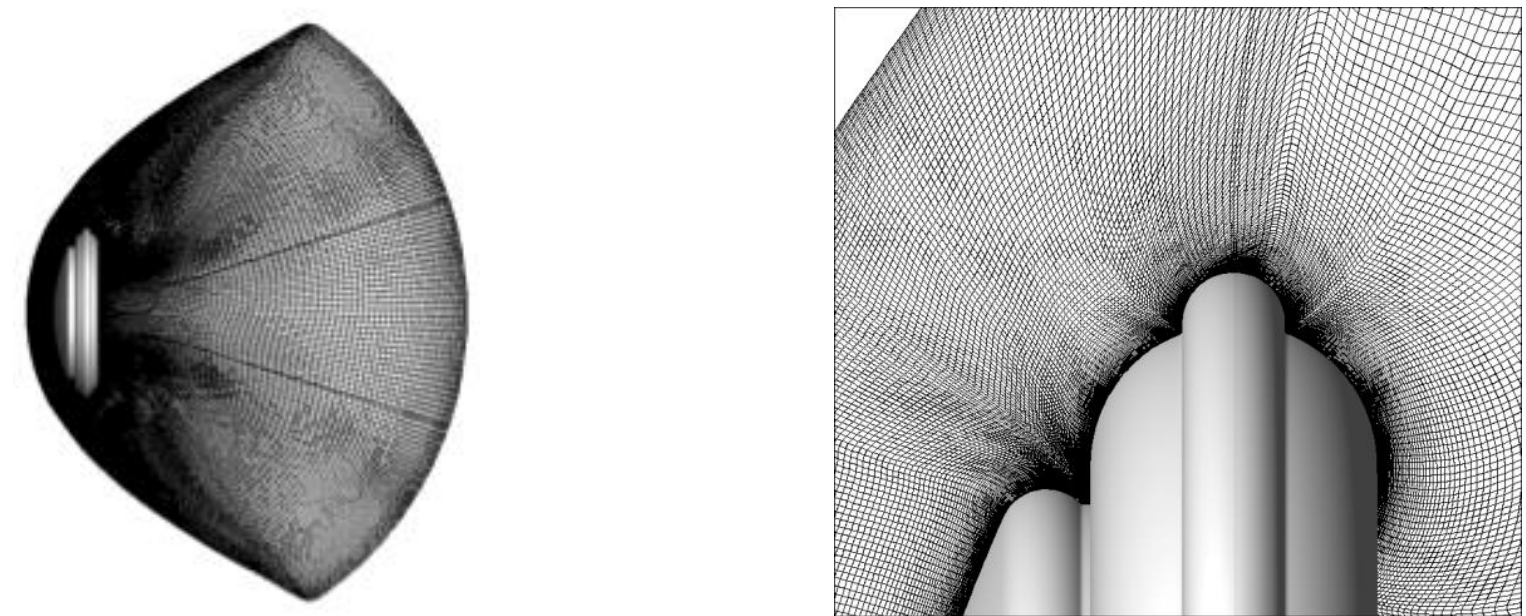

Figure 7. Plot of a shock aligned volume grid on the pitch plane (left) and a close-up view (right) 

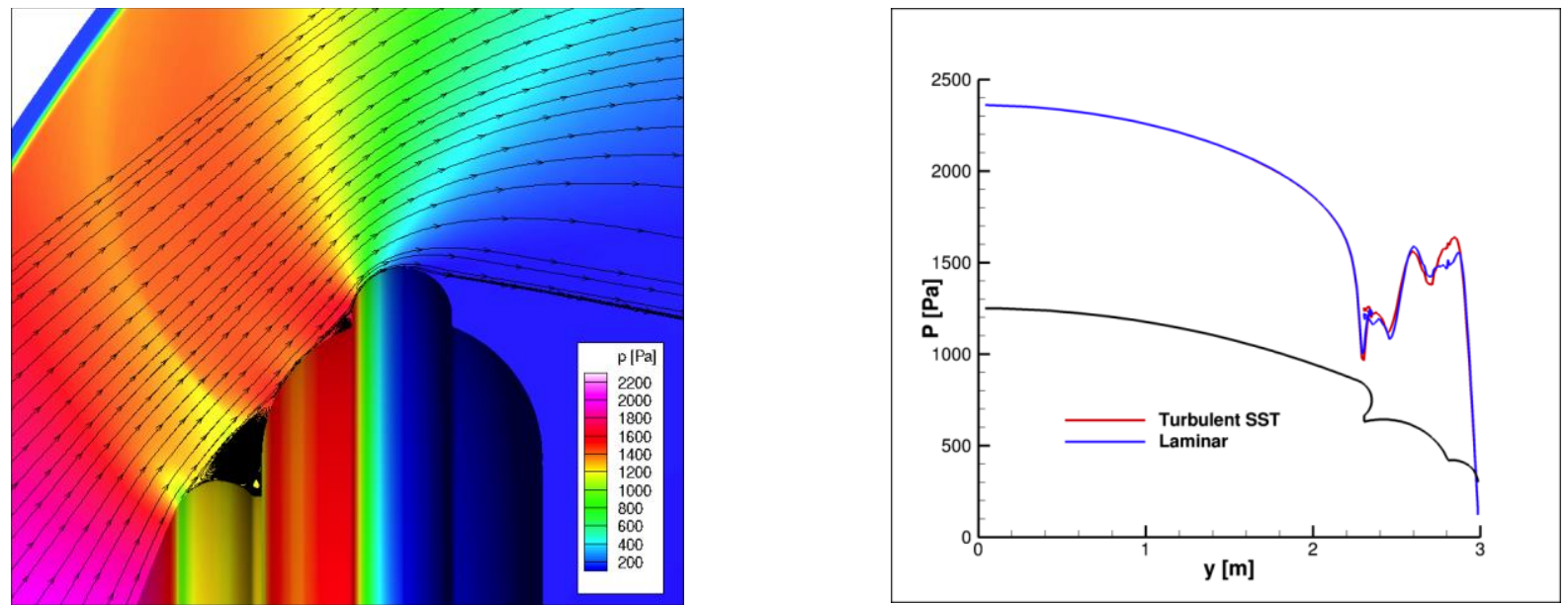

Figure 8. Pressure contours with streamlines on the pitch plane (left) and pressure distributions (right) for $\mathrm{M}_{\infty}=3.97$ at $\mathrm{AOA}=0 \mathrm{deg}$.
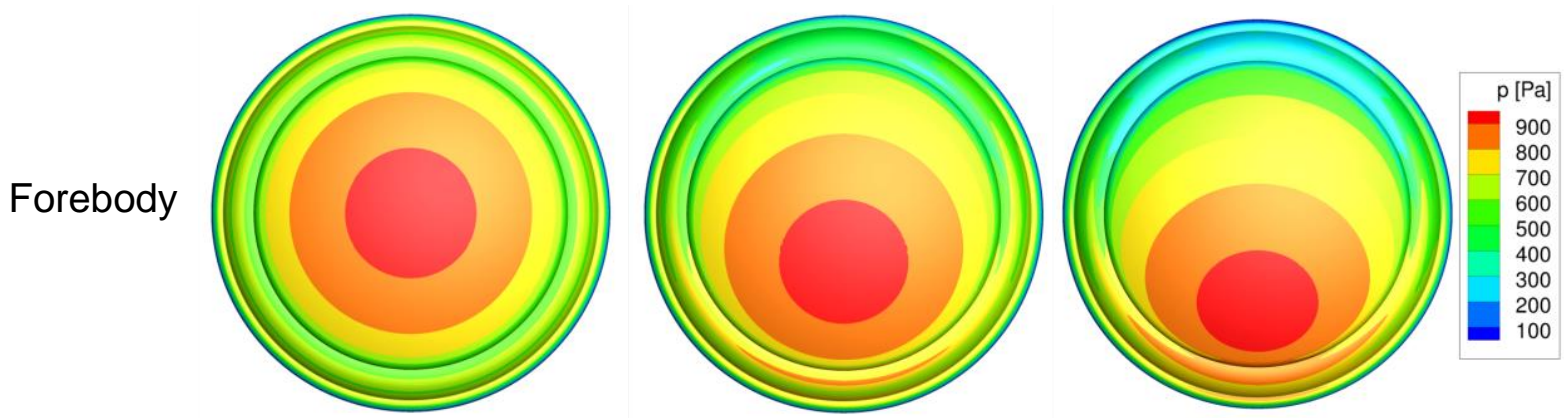

$$
\text { = } 0 \text { deg. }
$$

$=10 \mathrm{deg}$.

$$
=20 \text { deg. }
$$

Aftbody
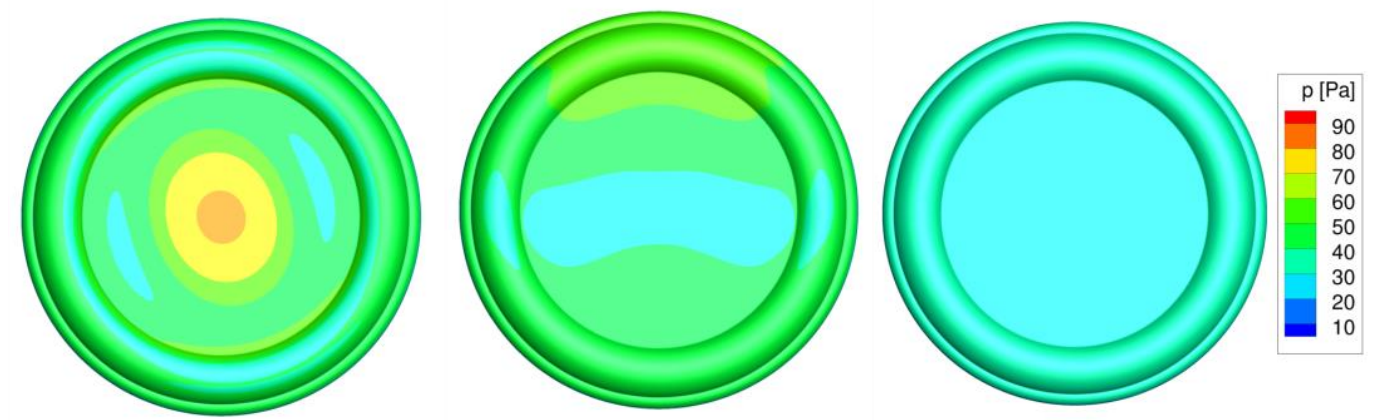

Figure 9. Averaged pressure contours on the forebody and aftbody $\left(M_{\infty}=2.12\right)$ 


\begin{tabular}{|c|c|c|c|c|c|c|c|}
\hline AOA & $\mathbf{M}_{\infty}$ & \multicolumn{3}{|c|}{ Full CFD } & \multicolumn{3}{c|}{ CFD $_{\text {forebody }}+$ Base Correction } \\
\hline & & $\mathrm{C}_{\mathrm{A}}$ & $\mathrm{C}_{\mathrm{N}}$ & $\mathrm{C}_{\mathrm{m}}$ & $\mathrm{C}_{\mathrm{A}}$ & $\mathrm{C}_{\mathrm{N}}$ & $\mathrm{C}_{\mathrm{m}}$ \\
\hline $0^{\circ}$ & 3.97 & 1.330 & 0.000 & 0.000 & 1.330 & 0.000 & 0.000 \\
\hline $10^{\circ}$ & 3.97 & 1.309 & 0.077 & -0.053 & 1.306 & 0.077 & -0.053 \\
\hline $20^{\circ}$ & 3.97 & 1.241 & 0.126 & -0.088 & 1.230 & 0.126 & -0.087 \\
\hline $0^{\circ}$ & 2.12 & 1.423 & 0.000 & 0.000 & 1.406 & 0.000 & 0.000 \\
\hline $10^{\circ}$ & 2.12 & 1.388 & 0.062 & -0.046 & 1.367 & 0.063 & -0.045 \\
\hline $20^{\circ}$ & 2.12 & 1.324 & 0.119 & -0.083 & 1.283 & 0.119 & -0.083 \\
\hline
\end{tabular}

Table 2 Comparison of full-body axisymmetric results with forebody solutions with base corrections

\section{Aftbody Geometries}

Since the STAR-48B rocket nozzle is the most prominent feature on the aftbody, the nozzle geometry was modeled (see Fig. 5) to study its effects on the overall aerodynamics of the test vehicle. Once again, the vehicle is assumed to be axisymmetric, and a hyperbolic volume grid (containing $\sim 13$ million grid points) was generated using Gridgen. SIAD-R simulations were computed for a range of angles of attack using the reference freestream conditions. A comparison of these rocket nozzle solutions with the previous full-body results is presented in Table 3 . An examination of the aerodynamic coefficients shows that the maximum differences between the two sets of solutions are less than $1 \%$ in all cases. In general, the surface pressures on the aftbody are very low at these supersonic conditions; thus, differences in the backshell geometry have minimal impact on the integrated forces and moments. Nevertheless, the backshell geometry may have a greater impact on the aerodynamics at higher angles of attack $\left(\alpha>30^{\circ}\right)$, particularly if a portion of the rocket nozzle is exposed to the freestream flow. Since the ADB allows for $\alpha$ to range from $0^{\circ}$ to $90^{\circ}$, the SIAD-R with the rocket nozzle aftbody was selected as the reference geometry for database simulations. To generate the aerodynamic database, turbulent SST simulations using DPLR were computed at the two reference conditions for $\alpha$ ranging from $0^{\circ}$ to $90^{\circ}$ in $15^{\circ}$ increments.

\begin{tabular}{|c|c|c|c|c|c|c|c|}
\hline AOA & $\mathbf{M}_{\infty}$ & \multicolumn{3}{|c|}{ SIAD-R with Flat Base } & \multicolumn{3}{c|}{ SIAD-R with Rocket Nozzle } \\
\hline & & $\mathrm{C}_{\mathrm{A}}$ & $\mathrm{C}_{\mathrm{N}}$ & $\mathrm{C}_{\mathrm{m}}$ & $\mathrm{C}_{\mathrm{A}}$ & $\mathrm{C}_{\mathrm{N}}$ & $\mathrm{C}_{\mathrm{m}}$ \\
\hline $0^{\circ}$ & 3.97 & 1.330 & 0.000 & 0.000 & 1.334 & 0.000 & 0.000 \\
\hline $10^{\circ}$ & 3.97 & 1.309 & 0.077 & -0.053 & 1.309 & 0.076 & -0.054 \\
\hline $20^{\circ}$ & 3.97 & 1.241 & 0.126 & -0.088 & 1.242 & 0.126 & -0.088 \\
\hline $30^{\circ}$ & 3.97 & 1.119 & 0.163 & -0.113 & 1.119 & 0.163 & -0.113 \\
\hline $0^{\circ}$ & 2.12 & 1.423 & 0.000 & 0.000 & 1.421 & 0.000 & 0.000 \\
\hline $10^{\circ}$ & 2.12 & 1.388 & 0.062 & -0.046 & 1.383 & 0.062 & -0.047 \\
\hline $20^{\circ}$ & 2.12 & 1.324 & 0.119 & -0.083 & 1.321 & 0.119 & -0.083 \\
\hline $30^{\circ}$ & 2.12 & 1.239 & 0.157 & -0.109 & 1.238 & 0.156 & -0.109 \\
\hline
\end{tabular}

Table 3 Comparison of SIAD-R solutions with different aftbody geometries

\section{Non-Axisymmetric Shapes}

Based on the previous results, it appears that the aftbody geometry has minor effects on the overall aerodynamics at cruise conditions. Instead of adding various aftbody components (such as spin-up/spin-down motors, video cameras, and PDD) to the CFD model, the next series of computations were focused on the effects of nonaxisymmetric forebody shapes. Laser scans of two fully inflated SIAD-R test articles were taken from ground-based inflation tests, and these scans were converted into CAD surfaces. Shown in Figure 10 is an example of a laserscanned surface for the second SIAD-R test article. As evident in the figure, the SIAD-R shape varied in the azimuthal direction and contained small surface features (such as thermocouple wiring tunnels). Because the laser scans only covered the inflatable sections of the SIAD-R, the rigid aeroshell and aftbody components were not included in the CAD files. Three non-axisymmetric volume grids were generated using the CAD surfaces. The first grid represented the first laser-scanned SIAD-R test article. The surface mesh points were clustered near the "ridges" formed by the gore sections (see Fig. 11 for the surface grid distribution), and the volume grid contained approximately 59 million grid points. Two grids were created for the second laser-scanned test article. These grids have a more uniform surface grid distribution. The baseline grid contained around 8 million mesh points while a 
finer version had approximately 25 million grid points. Since the laser-scanned files contained only the torus and burble fence of the SIAD-R, a rigid forebody and a flat base aftbody were added to the CAD surfaces to define an enclosed vehicle.

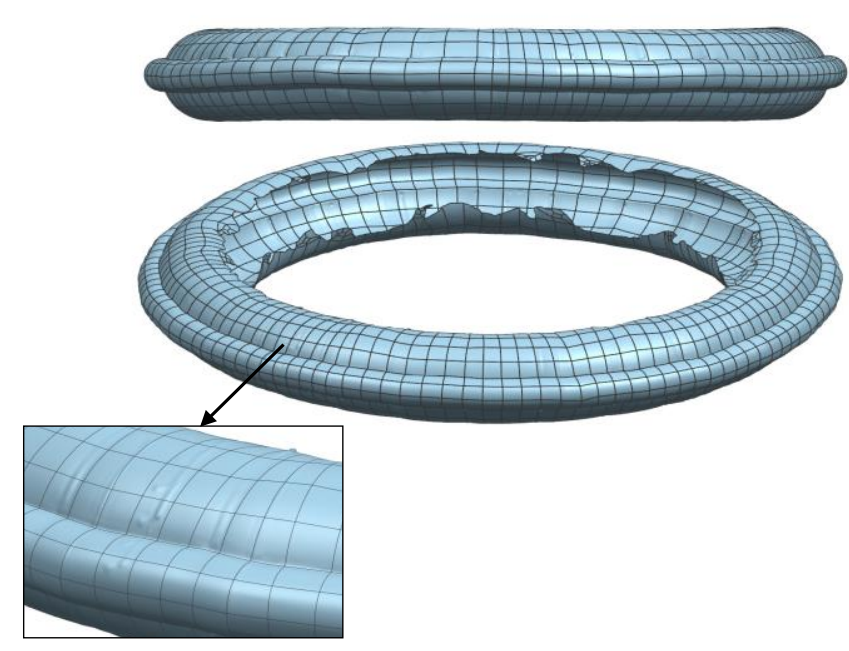

Figure 10. Second laser-scanned SIAD-R geometry. Close-up view showing small surface features (such as thermocouple wiring tunnels)

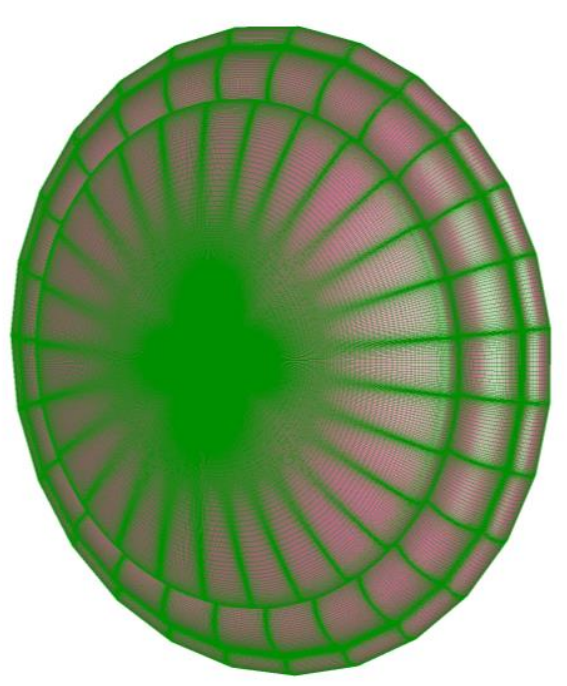

Figure 11. CFD surface grid (green) with CAD database (magenta) for the first laserscanned geometry

A comparison of the forces and moments (tabulated in Table 4) shows minor aerodynamic differences between the laser-scanned geometries and the aerodynamic database developed using CFD solutions on an axisymmetric shape with a rocket nozzle aftbody. In fact, the maximum differences between the laser-scanned solutions and the ADB values are less than $3 \%$ for all cases. Another check of the non-axisymmetric shapes involved running a series of simulations to look at the sensitivity of the SIAD-R "clock" angle orientation with respect to the freestream flow. The second laser-scanned geometry was rotated around its $\mathrm{x}_{\mathrm{ac}}$ axis (see drawing in Table 5 for a definition of the Aerodynamic Coordinate system) at angles of $0^{\circ}, 45^{\circ}, 90^{\circ}, 135^{\circ}$, and $180^{\circ}$. Turbulent SST simulations at $\mathrm{M}_{\infty}=3.97$ and $\alpha=15^{\circ}$ were performed on both the baseline and fine volume grids. Analysis of these CFD solutions showed that the maximum variations in the force and moment coefficients were observed for a $90^{\circ}$ clock angle, and those coefficients (along with the corresponding database values) are listed in Table 5. The maximum differences between the second laser-scanned geometry at various clock angles and the database values are less than $2 \%$ for all cases.

In general, comparisons between the database values and laser-scanned solutions showed that ADB values for $\mathrm{C}_{\mathrm{A}}$ are slightly higher ( 1\%) with maximum differences of $2 \%-3 \%$ for all integrated forces and moments. Based on these results, no corrections were made to the database to account for differences due to non-axisymmetric shapes or small features on the aftbody. Instead, these differences are factored into the aerodynamic uncertainty models. As detailed in Ref. 10, the aerodynamic uncertainties (on the order $\pm 10 \%$ for $\mathrm{C}_{\mathrm{A}}, \mathrm{C}_{\mathrm{N}}$ and $\pm 20 \%$ for $\mathrm{C}_{\mathrm{m}}$ ) are formulated along the scheme used for MSL.

\begin{tabular}{|c|c|c|c|c|c|c|c|c|c|}
\hline & \multicolumn{3}{|c|}{$\begin{array}{c}2^{\text {nd }} \\
\text { Laser Scan Solution } \\
\text { (baseline grid) }\end{array}$} & \multicolumn{3}{|c|}{$\mathbf{1}^{\text {st }}$ Laser Scan Solution } & \multicolumn{4}{c|}{ Database Values } \\
\hline & $\mathrm{C}_{\mathrm{A}}$ & $\mathrm{C}_{\mathrm{N}}$ & $\mathrm{C}_{\mathrm{m}}$ & $\mathrm{C}_{\mathrm{A}}$ & $\mathrm{C}_{\mathrm{N}}$ & $\mathrm{C}_{\mathrm{m}}$ & $\mathrm{C}_{\mathrm{A}}$ & $\mathrm{C}_{\mathrm{N}}$ & $\mathrm{C}_{\mathrm{m}}$ \\
\hline $0^{\circ}$ & 1.331 & 0.001 & -0.001 & 1.326 & 0.000 & 0.000 & 1.334 & 0.000 & 0.000 \\
\hline $15^{\circ}$ & 1.281 & 0.104 & -0.072 & 1.276 & 0.101 & -0.071 & 1.282 & 0.104 & -0.072 \\
\hline $30^{\circ}$ & 1.117 & 0.164 & -0.113 & 1.115 & 0.163 & -0.113 & 1.119 & 0.163 & -0.113 \\
\hline
\end{tabular}

Table 4 Comparison of laser-scanned SIAD-R solutions with aerodynamic database (turbulent SST model, $M_{\infty}=3.97$ ) 


\begin{tabular}{|c|c|c|c|c|c|c|}
\hline $\begin{array}{c}\text { Clock Angle } \\
\text { (around x axis) }\end{array}$ & \multicolumn{3}{|c|}{ Force Coefficients } & \multicolumn{3}{c|}{ Moment Coefficients } \\
\hline & $\mathrm{C}_{\mathrm{x}}$ & $\mathrm{C}_{\mathrm{y}}$ & $\mathrm{C}_{\mathrm{z}}$ & $\mathrm{Cm}_{\mathrm{x}}$ & $\mathrm{Cm}_{\mathrm{y}}$ & $\mathrm{Cm}_{\mathrm{z}}$ \\
\hline $0^{\circ}$ (baseline grid) & -1.281 & 0.000 & -0.104 & 0.000 & -0.072 & 0.000 \\
\hline $0^{\circ}$ (fine grid) & -1.276 & -0.001 & -0.106 & 0.000 & -0.072 & 0.000 \\
\hline $90^{\circ}$ (baseline grid) & -1.278 & 0.002 & -0.103 & 0.000 & -0.072 & -0.001 \\
\hline $90^{\circ}$ (fine grid) & -1.274 & 0.002 & -0.105 & 0.000 & -0.072 & -0.001 \\
\hline Database & -1.282 & 0.000 & -0.104 & 0.000 & -0.072 & 0.000 \\
\hline
\end{tabular}

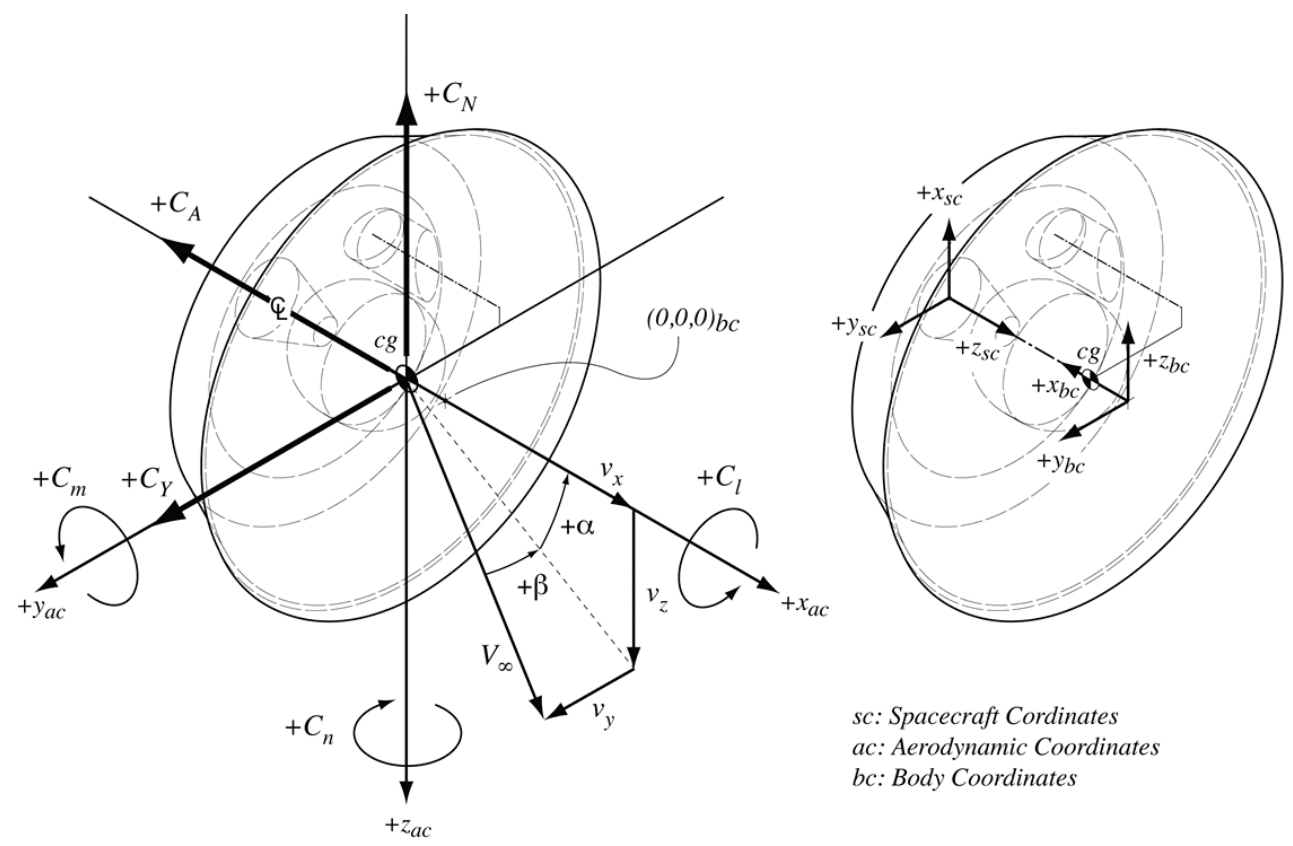

Table 5 Diagram of coordinate systems and comparison of second laser-scanned SIAD-R solutions with database (turbulent SST model, $M_{\infty}=3.97, \alpha=15 \mathrm{deg}$.)

\section{B. Comparison to Hypervelocity Free-Flight Aerodynamics Facility Test Data}

A series of free-flight aerodynamics ground tests were conducted for the SIAD-R in the Hypervelocity FreeFlight Aerodynamics Facility (HFFAF) at NASA Ames Research Center. The HFFAF test section is $22.9 \mathrm{~m}$ long, $0.99 \mathrm{~m}$ in diameter, and it is equipped with 16 shadowgraph-imaging stations spaced at $1.52 \mathrm{~m}$ intervals. For this test, 37 shots of a deployed SIAD models (diameter $=3.56 \mathrm{~cm}$ ) and 12 shots of a stowed configuration (diameter $=$ $1.7 \mathrm{~cm}$ ) were fired in the HFFAF. For the deployed model tests, the Mach number ranged from 2.03 to 3.85 with $\alpha$ of $0.7^{\circ}$ to $20.7^{\circ}$. For the stowed configuration tests, the Mach number varied from 3.16 to 3.67 with $\alpha$ of $1.6^{\circ}$ to $16.9^{\circ}$. Shown in Figure 12 are examples of the digitized shadowgraphs collected at the image stations. These digitized images were read by the CADRA $1^{7}$ system, a film-reading program that automatically measures the model's position and orientation in each shadowgraph. The information is then extracted and fitted (see Chapman ${ }^{8}$ for more details on the data extraction process) to determine static and dynamic aerodynamic coefficients as a function of Mach number and angle of attack.

For comparison purposes, a set of CFD simulations were computed at two test shot condtions ${ }^{9}$ (Shot \#2614: $\mathrm{M}_{\infty}$ $=2.32, \rho_{\infty}=0.263 \mathrm{~kg} / \mathrm{m}^{3}, \mathrm{~T}_{\infty}=293 \mathrm{~K}$ and Shot \#2651: $\left.\mathrm{M}_{\infty}=2.84, \rho_{\infty}=0.24 \mathrm{~kg} / \mathrm{m}^{3}, \mathrm{~T}_{\infty}=294.6 \mathrm{~K}\right)$ for $\alpha=0^{\circ}, 10^{\circ}$, and $20^{\circ}$. A volume grid containing approximately 3.7 million grid points was specifically created to model the deployed test configuration. This test model (shown in Fig. 13) is an early iteration of the SIAD-R design so the geometry differs slightly from the flight vehicle flown on SFTD-1. Turbulent SST simulations using DPLR were computed for the two test conditions, and Fig. 14 shows a typical solution of the Mach contours at the pitch plane. 

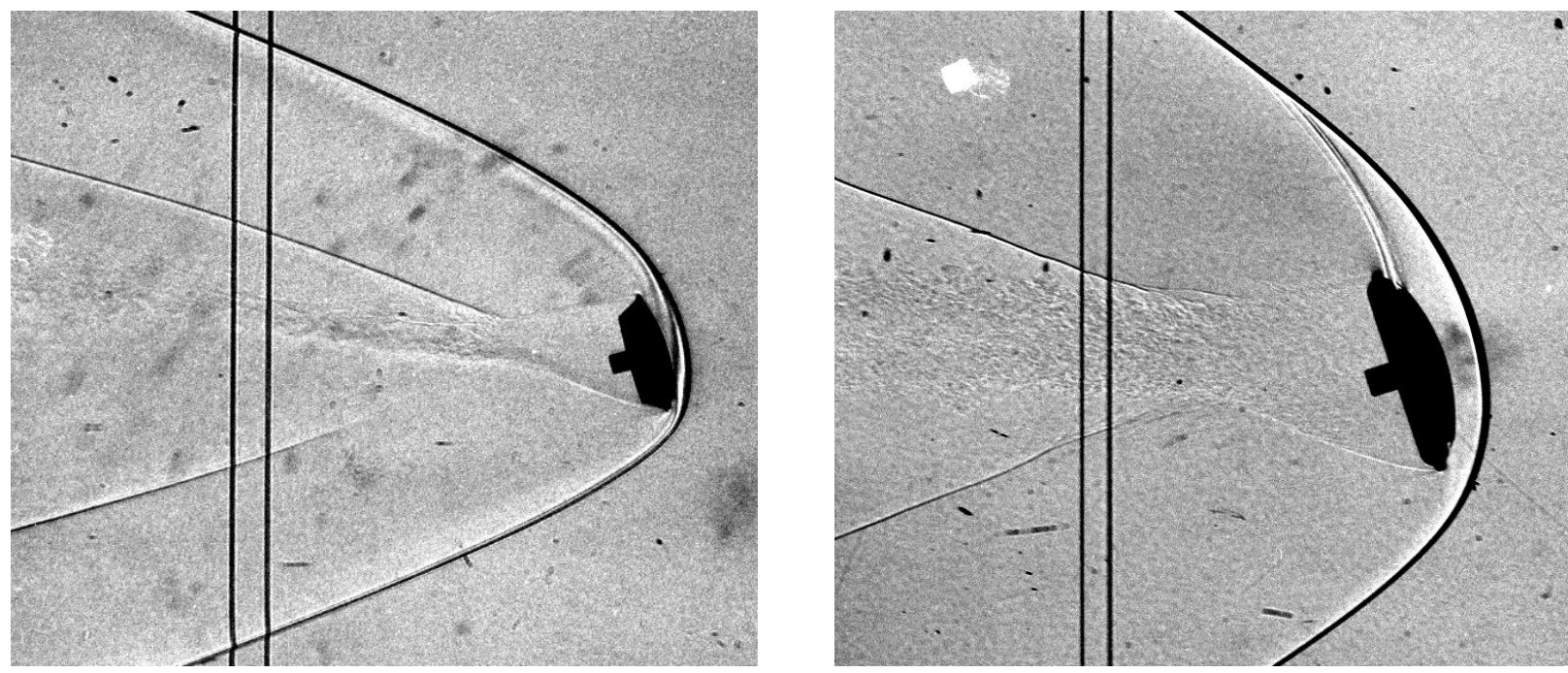

Figure 12. Digitized shadowgraphs of SIAD-R test models in ballistic range: stowed (left) and deployed (right) configurations
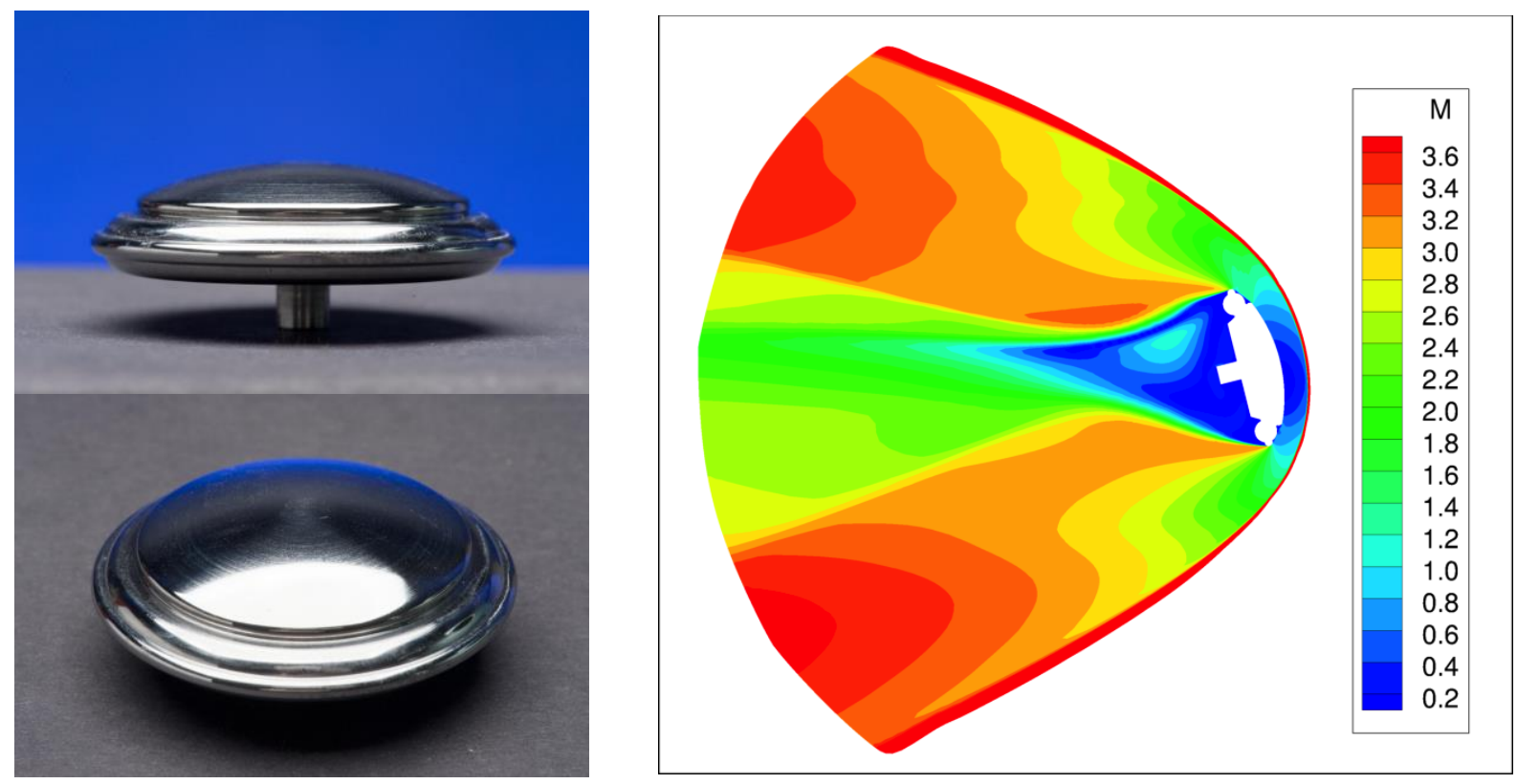

Figure 13. Deployed SIAD-R Model Figure 14. CFD ballistic range solution (Mach contours at tested in ballistic range (diameter $=3.56 \mathrm{~cm})$ the pitch plane, $M_{\infty}=3.84, \alpha=10^{\circ}$ )

Comparisons of lift and drag coefficients between the ballistic range data and CFD results are plotted in Fig. 15. The solid blue $\left(\mathrm{M}_{\infty}=3.84\right)$ and red lines $\left(\mathrm{M}_{\infty}=2.32\right)$ represent least-squares fit of the test data, and the dashed lines include the maximum uncertainties of the curve fit coefficients. It should be noted that the dashed lines represent only the uncertainties in the coefficients of the least-squares fit (assuming a quasi-linear model) so they do not encompass all the uncertainties in the HFFAF test data. The uncertainties in the curve fits are greater at $\mathbf{M}_{\infty}=3.84$ because there were fewer test shots at the higher Mach number. In general, the predicted drag agreed well with the least-squares fits, with maximum differences of $1.5 \%$. The CFD solutions tend to predict a slightly lower drag coefficient than the test data. Differences in the lift coefficient were higher $\left(\sim 11 \%\right.$ at $\left.\alpha=20^{\circ}\right)$. At $\mathrm{M}_{\infty}=3.84$, the predicted $C_{L}$ value is within the uncertainty bands of the least-square fit. For the $M_{\infty}=2.32$ case, the CFD lift coefficient is still lower than the curve fits (by $\sim 7.5 \%$ at $\alpha=20^{\circ}$ ). Further studies are underway to examine the differences between the HFFAF test data and CFD solutions. 

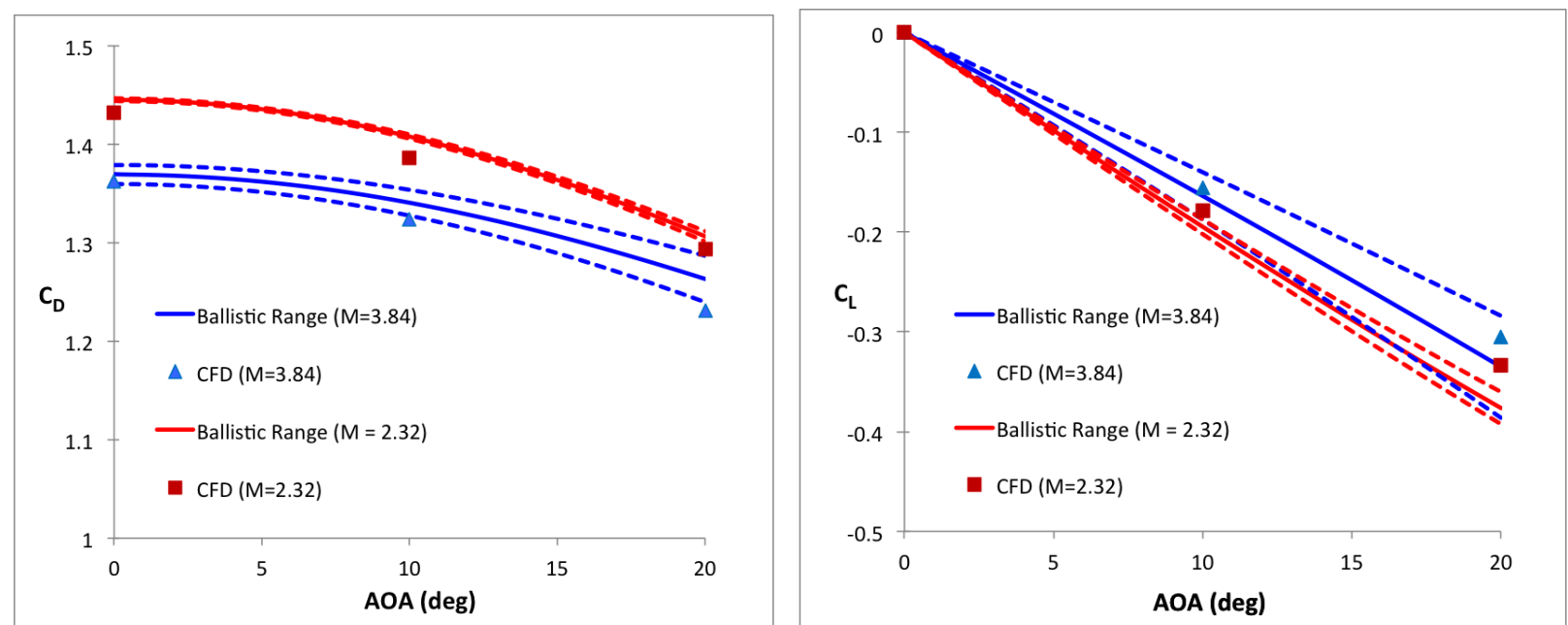

Figure 15. Comparison of CFD simulations with ballistic range least-squares curve fits (dashed lines include uncertainties in the curve fit coefficients)

\section{Comparison to SFDT-1 Flight Data}

The successful deployment and testing of SIAD in SFDT-1 provided valuable performance data for model validation. The details of flight performance, instrumentation, reconstruction, and assembly of the aerodatabase are discussed elsewhere ${ }^{1,2,10}$. Figure 16 shows the reconstruction of a Best Estimated Trajectory (BET) with lines highlighting major flight events. In this paper we compare our predictions of key performance parameters of the aerodynamic decelerator: namely the axial force coefficient and its static stability. Dyanmic stability (pitch damping) characteristics are discussed in Ref. 10. Five flight conditions (see Table 6) were selected from the BET for post-flight simulations. In an attempt to represent the SIAD-R geometry more precisely, a new CFD grid was created by combining the first laser-scanned CAD surface with an axisymmetric rocket nozzle (see Fig. 17 for plots of the surface geometry). The new volume mesh (containing $\sim 65$ million grid points) was used for all post-flight analysis.

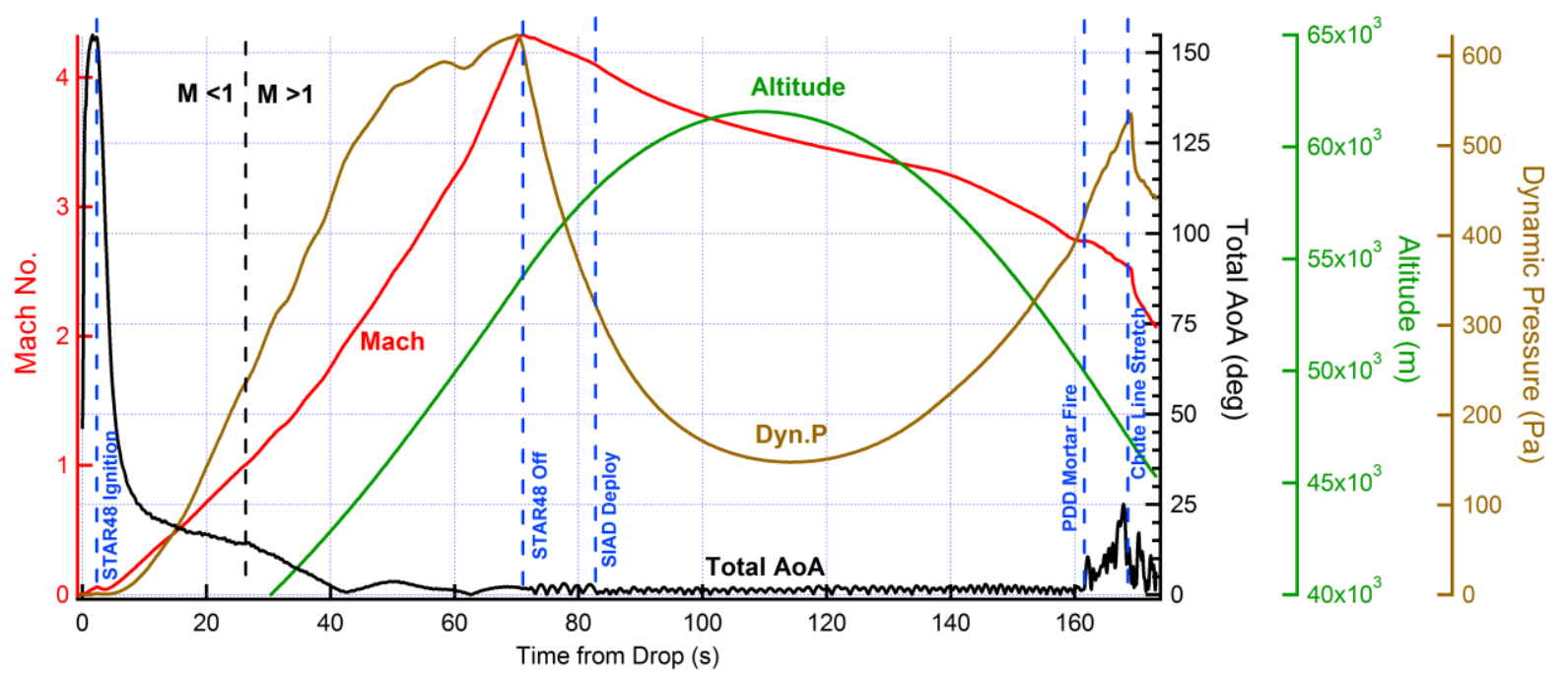

Figure 16. Best Estimated Trajectory of SFDT-1

Figure 18 shows a comparison of axial force coefficient, $\mathrm{C}_{\mathrm{A}}$, reconstructed from the SIAD phase of the flight with CFD simulations at flight conditions listed in Table 6. The CFD $\mathrm{C}_{\mathrm{A}}$ values are evaluated at 0-deg angle of attack for comparisons, which is acceptable since the reconstructed vehicle attitude did not exceed beyond 3-deg, 
which is expected to bring a minimal change to $\mathrm{C}_{\mathrm{A}}$. The reconstructed vehicle angle of attack, the side-slip angle, dynamic pressure, and Mach number are also shown. The $\mathrm{C}_{\mathrm{A}}$ predictions for both laminar and turbulent flow conditions are plotted, although the difference between them is small (see Table 7). The $\mathrm{C}_{\mathrm{A}}$ comparisons between $\mathrm{CFD}$ and reconstructed values are in very good agreement (maximum difference $\sim 3 \%$ ). A gradual increase in $\mathrm{C}_{\mathrm{A}}$ with decreasing Mach number is reproduced in both CFD and flight. The flight reconstructed $\mathrm{C}_{\mathrm{A}}$ however, shows a weak dependence on dynamic pressure which is not seen in CFD. This weak dependence is within the uncertainty of the flight reconstruction.

\begin{tabular}{|c|c|c|c|c|c|c|c|}
\hline Case & Time $(\mathbf{s})$ & $\mathbf{V}_{\infty}(\mathbf{m} / \mathbf{s})$ & $\boldsymbol{\rho}_{\infty}\left(\mathbf{g} / \mathbf{m}^{\mathbf{3}}\right)$ & Altitude $(\mathbf{m})$ & $\mathbf{P}_{\infty}(\mathbf{P a})$ & $\mathbf{T}_{\infty}(\mathbf{K})$ & $\mathbf{M}_{\infty}$ \\
\hline 1 & 89.18 & 1207 & 0.328 & 59600 & 22.26 & 236.5 & 3.92 \\
\hline 2 & 106.08 & 1102 & 0.255 & 61520 & 16.92 & 231.2 & 3.62 \\
\hline 3 & 128.48 & 1036 & 0.315 & 59910 & 21.32 & 235.7 & 3.37 \\
\hline 4 & 156.48 & 928.2 & 0.825 & 51960 & 62.24 & 262.8 & 2.86 \\
\hline 5 & 168.68 & 819.8 & 1.576 & 47000 & 117.74 & 260.3 & 2.54 \\
\hline
\end{tabular}

Table 6 Selected flight conditions from BET for post-flight CFD simulations
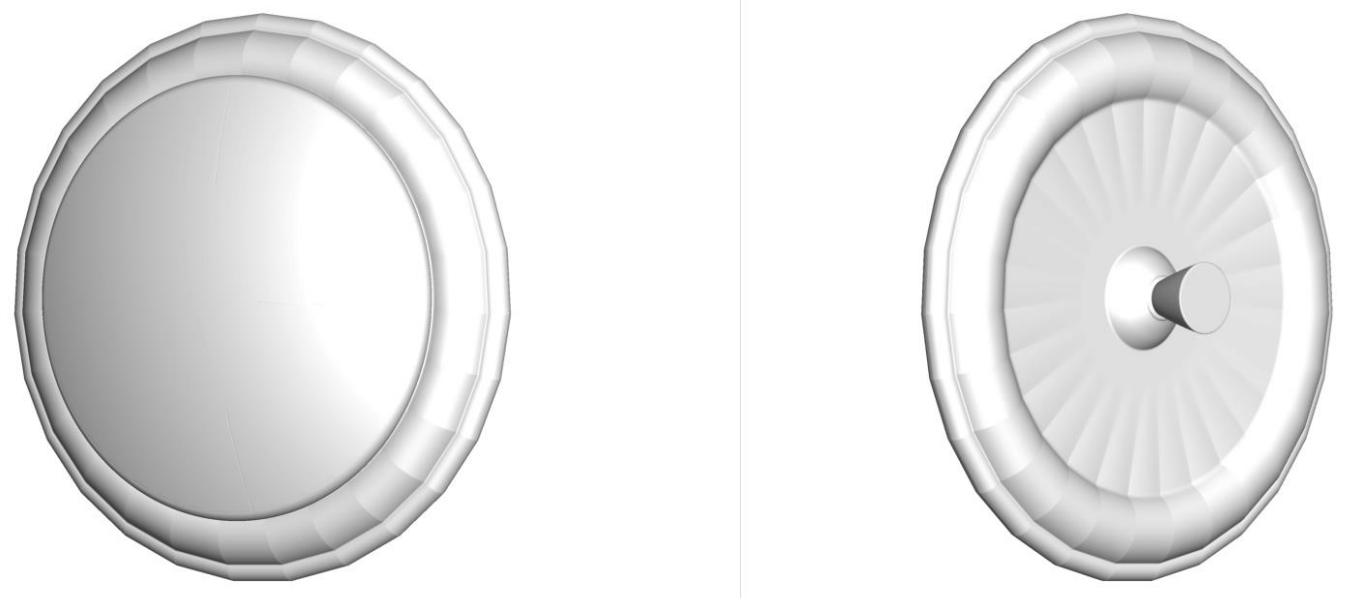

Figure 17. Modified laser-scanned SIAD-R geometry and rocket nozzle aftbody - Forebody (left) and Backshell (right)

Initial comparisons of the pitching moment between the $\mathrm{ADB}$ and reconstructed flight data showed some discrepancies at small angles of attack. A closer look at $C_{m}$ suggests that the $15^{\circ}$ increments used for $\alpha$ in the ADB is too coarse for accurate interpolations at small angles of attack. As a result, additional axisymmetric solutions at $\alpha$ $=2^{\circ}$ for $\mathrm{M}_{\infty}=3.0$ and 2.12 were added to the aerodynamic database. Figure 19 shows the variation of the normal force coefficient and the restoring pitching moment coefficient with angles of attack at around Mach 3.0. The moment coefficient is evaluated at the vehicle's center of gravity. The CFD predicted normal force and the restoring moment are found to be in excellent agreement with the flight reconstruction. The static stability coefficient $\mathrm{dCmcg} / \mathrm{d} \alpha$ from the flight reconstruction is about $-0.00445 / \mathrm{deg}$. versus $-0.00415 / \mathrm{deg}$. from CFD. In addition to validating the CFD results, the excellent comparison in the static stability coefficient provides indirect confirmation that the SIAD achieved its desired shape and maintained it without deformation or compliance during vehicle attitude oscillations. 


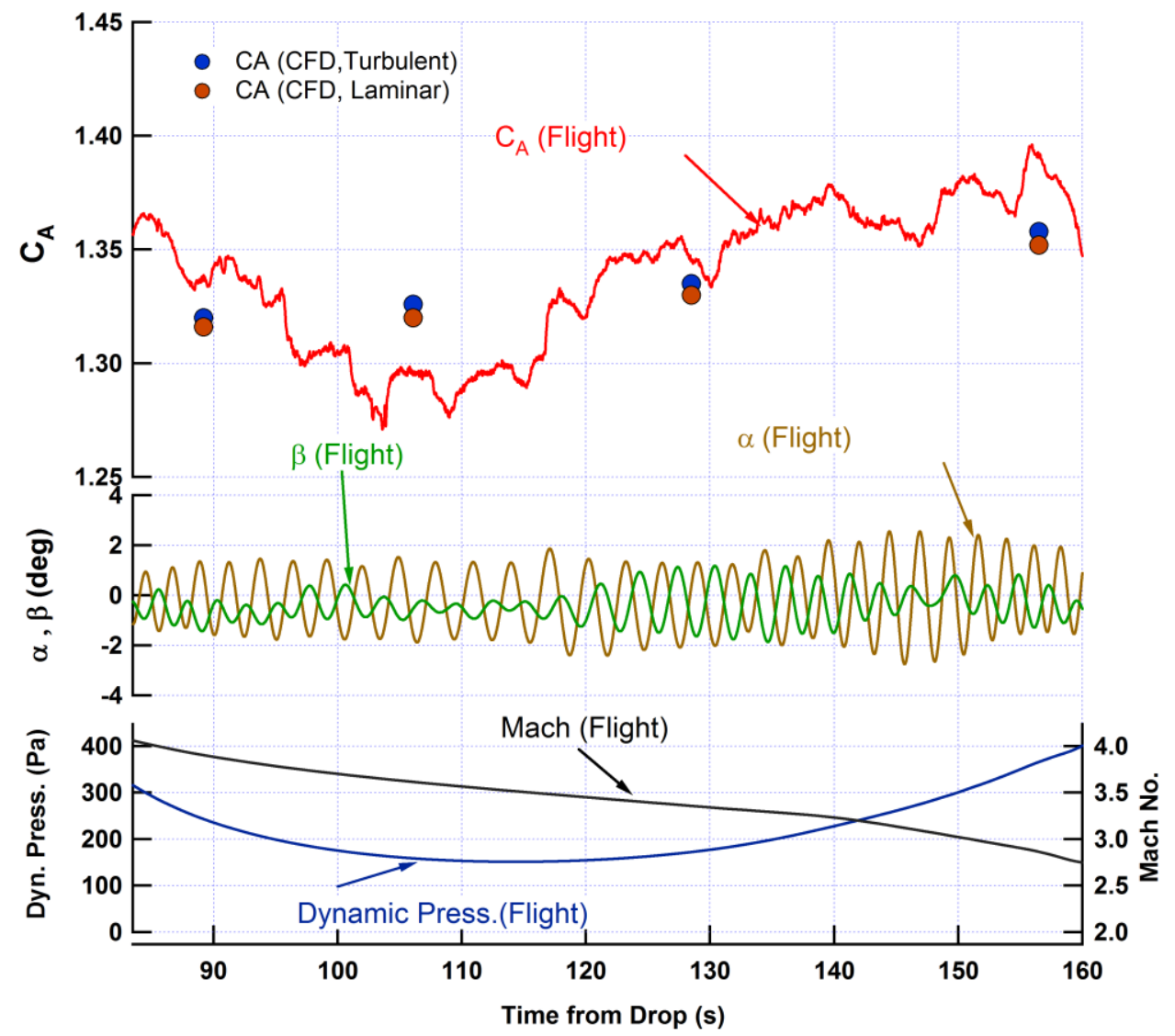

Figure 18. Comparisons of axial force coefficients as reconstructed from flight and as predicted with CFD
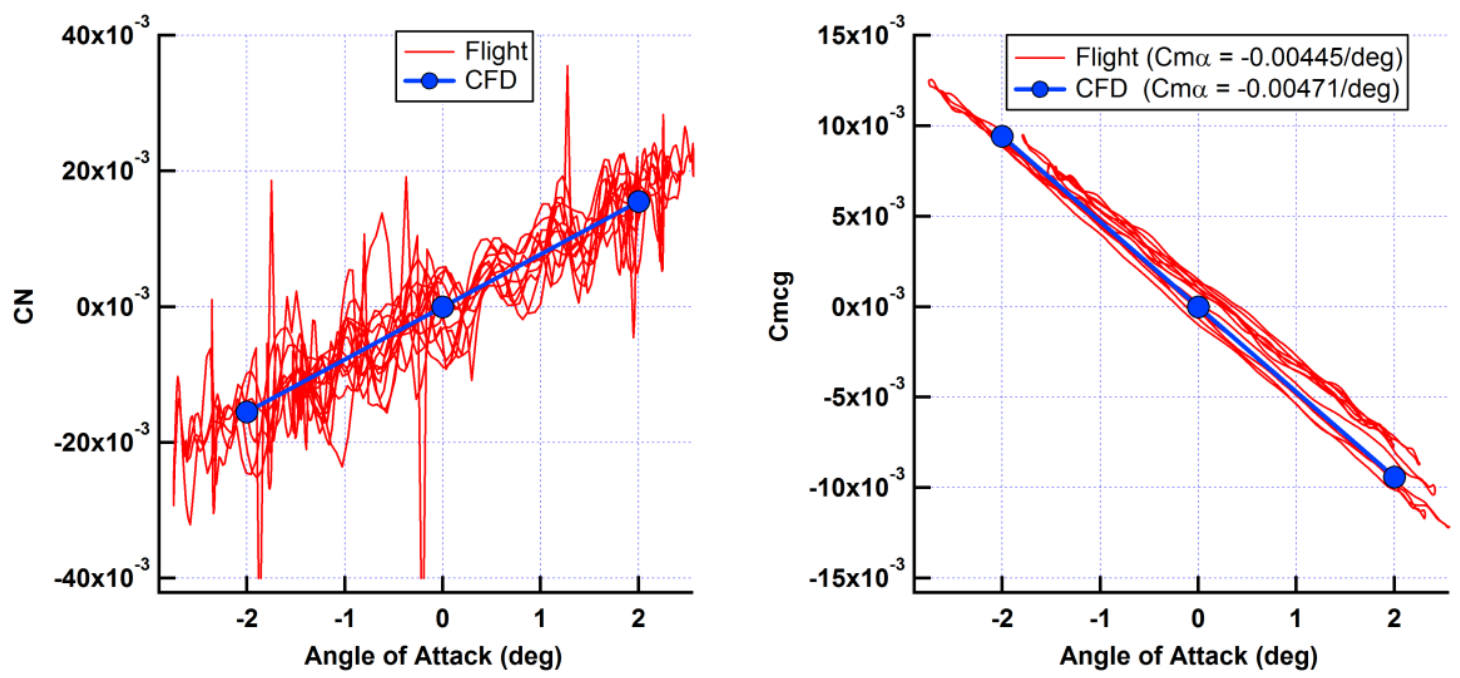

Figure 19. Comparisons of (a) Normal force coefficient and (b) pitching moment coefficient at Mach 3.0 as reconstructed from flight and as predicted with CFD 


\begin{tabular}{|c|c|c|c|c|c|c|}
\hline Case & Time (s) & $\mathbf{M}_{\infty}$ & $\mathbf{C}_{\mathbf{A}}(\mathbf{A D B})$ & $\begin{array}{c}\text { Turbulent SST } \\
\mathbf{C}_{\mathbf{A}}(\mathbf{C F D})\end{array}$ & $\begin{array}{c}\text { Laminar } \\
\mathbf{C}_{\mathbf{A}}(\mathbf{C F D})\end{array}$ & $\begin{array}{c}\text { Difference in } \mathbf{C}_{\mathbf{A}} \\
\text { between ADB and } \\
\text { Post-flight results }\end{array}$ \\
\hline 1 & 89.18 & 3.92 & 1.336 & 1.320 & 1.316 & $1.2 \%$ \\
\hline 2 & 106.08 & 3.62 & 1.349 & 1.326 & 1.320 & $1.7 \%$ \\
\hline 3 & 128.48 & 3.37 & 1.361 & 1.335 & 1.330 & $1.9 \%$ \\
\hline 4 & 156.48 & 2.86 & 1.386 & 1.358 & 1.352 & $2.0 \%$ \\
\hline 5 & 168.68 & 2.54 & 1.411 & 1.377 & 1.370 & $2.4 \%$ \\
\hline
\end{tabular}

Table 7 Comparison of axial coefficients between post-flight CFD simulations vs. aerodynamic database

\section{Aerothermal Analysis}

In addition to aerodynamics, DPLR was also used to estimate surface heat flux on the SIAD-R. Laminar and turbulent simulations (using turbulent SST and Baldwin-Lomax models) were performed to study the aerothermal environment of the SIAD-R. Shown in Fig. 20 is plot of the laminar and turbulent SST heat flux at the surface of the SIAD-R (axisymmetric shape with $\alpha=0^{\circ}$ ). As evident from the graph, localized hot spots are predicted at the torus and burble flow impingement/reattachment locations. Since turbulent SST simulations typically produced the highest heat flux when compared with the corresponding laminar and turbulent B-L solutions, the SST results were selected to provide the most conservative heating estimates in designing the SIAD-R.

Two sets of CFD simulations were computed to study the aerothermal differences between axisymmetric and laser-scanned geometries. Plotted in Fig. 21 is time-averaged heating contours on the forebodies of the SIAD-R at $\mathrm{M}_{\infty}=3.97 ; \alpha=0^{\circ}, 15^{\circ}$, and $30^{\circ}$; and $\mathrm{T}_{\mathrm{w}}=300 \mathrm{~K}$. The heating contours show that local, three-dimensional geometric features of the SIAD-R (from the first laser-scanned geometry) may result in higher heating than an idealized axisymmetric model. The heat flux differences between the axisymmetric and laser-scanned geometries also increased with angle of attack, and it can be $39 \%$ higher than the corresponding axisymmetric value at $\alpha=30^{\circ}$. Based on these calculations, an augmentation factor of 1.4 is included in the heating indicators to account for these

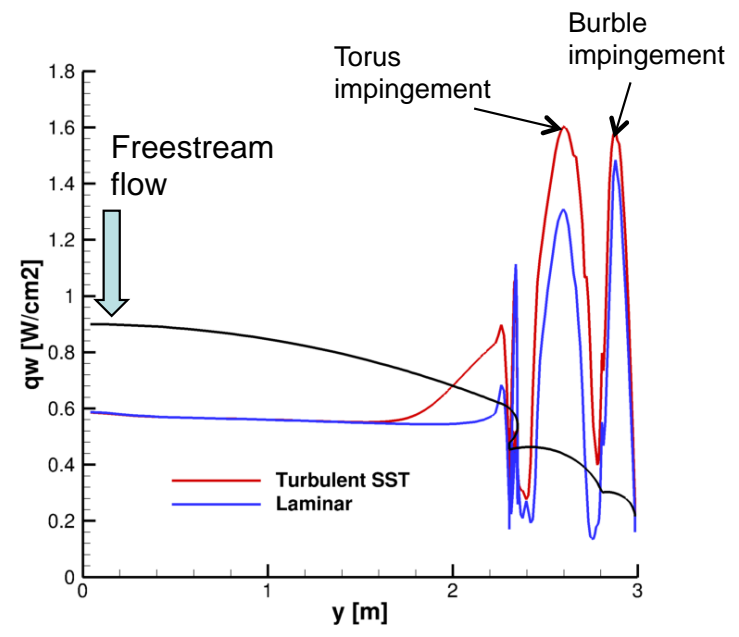

Figure 20. Surface heat flux on the SIAD-R. High heating occurs at the flow impingement points.

local heating maxima seen in non-axisymmetric shapes.

For the aerothermal database, CFD simulations on the reference axisymmetric SIAD-R geometry were computed at several altitudes, freestream velocities, and fabric wall temperatures. Surface heat flux at 7 thermocouple (TC) locations (see Fig. 22 for a TC layout) were extracted, and a least-squares minimization process was used to determine the constants ( $\mathrm{Cl}$ to $\mathrm{C} 3$ ) for the heating indicators, which are functions of the freestream density $(\rho)$ and velocity $(v)$, and wall temperature $(\mathrm{Tw})$.

$$
q_{w, \text { ind }}=C 1 \rho^{C 2} v^{C 3}+C 4 \rho^{C 2} v\left(T_{\text {wall }}-300\right)
$$




$$
q_{w, i n d, \alpha>0}=q_{w, i n d, \alpha=o}\left(1+e \alpha+f \alpha^{2}\right)
$$

A second order polynomial function (Eq. 2) is used to account for angle of attack effects. These indicators were then applied as inputs in a thermal response model (see Muppidi ${ }^{11}$ for a detailed description) to predict the fabric wall temperature as a function of time.

For post-flight analysis, laminar and turbulent simulations using 5 freestream conditions (see Table 6) were computed on the modified laser-scanned SIAD-R geometry (configuration shown in Fig. 17). Once again, a leastsquares process was used to evaluate the constants for the heat flux indicators. The updated indicators were fed into the thermal response model (a 1.4 augmentation factor was not used in these calculations since the laser-scanned geometry accounted for non-axisymmetric effects). The average fabric wall temperatures are plotted in Figure 23, and the predicted temperatures are well below the design limit of $300^{\circ} \mathrm{C}$. Comparisons of the flight data and predicted temperature profiles (using laminar CFD heat fluxes) for TC1 and TC2 are shown in Fig. 24 (plots at all 7 TC locations are available in Ref. 11). The three solid curves in Figure 24 correspond to the temperature traces at three gore locations $(2,11$, and 20). The plots also show the two temperatures predicted by the thermal response model: "Model-TC", the predicted thermocouple temperature is consistently lower than "Model", the predicted fabric temperature for all the thermocouples. Both models predict higher temperatures than the thermocouple data, with the highest over-prediction of $\sim 35^{\circ} \mathrm{C}$ (TC2). In general, the post-flight heating indicators and the thermal response model did a reasonable job in estimating the temperature response at the TC locations. As discussed in Ref. 11 , the slopes of the predicted temperature curve and the thermocouple traces are quite different (especially during the initial rise and during the post-peak drop in temperature). Further studies are underway to improve the thermal response model and the aerothermal modeling using CFD.
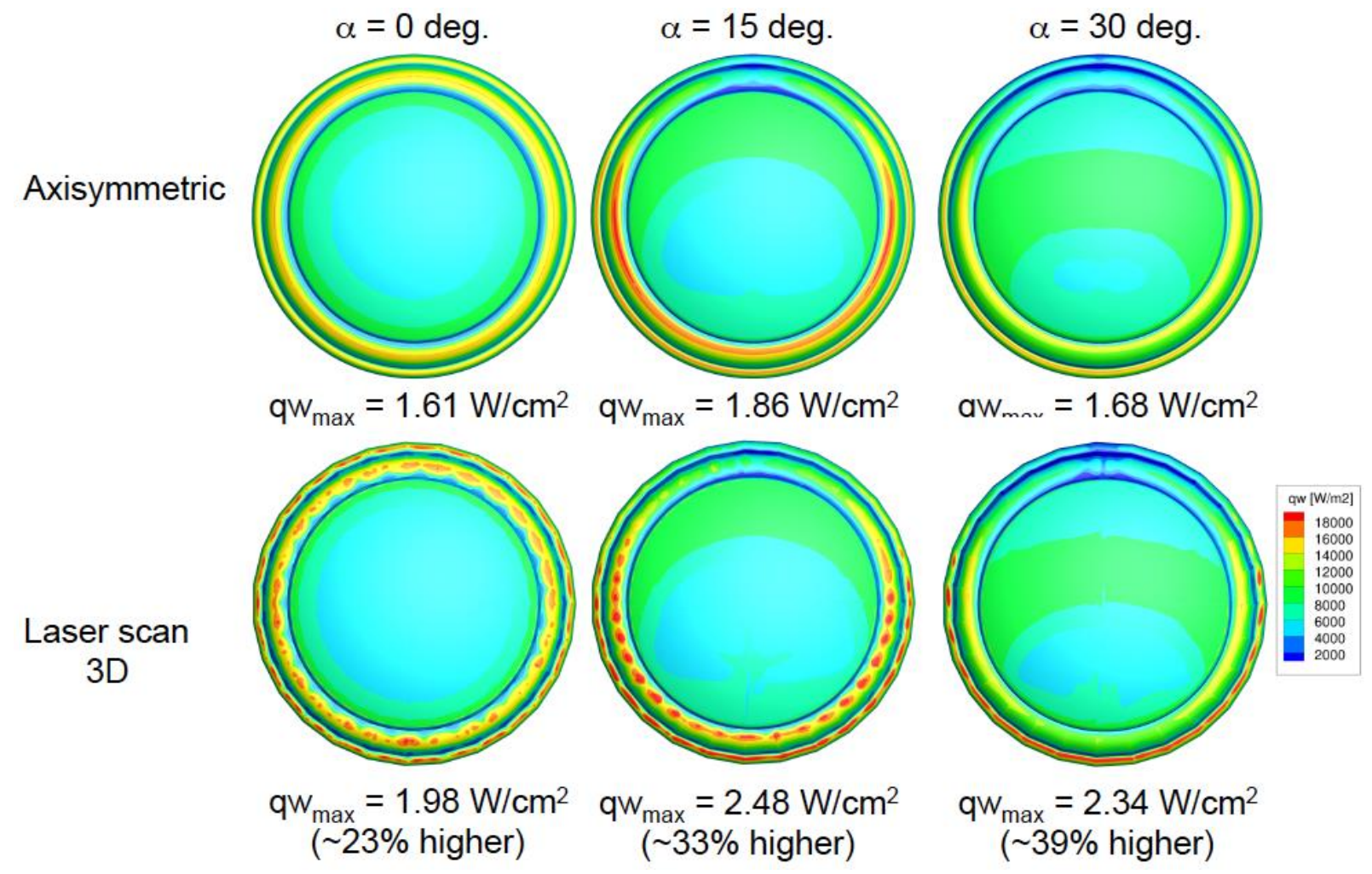

Figure 21. Surface heating Rates from axisymmetric and laser scan solutions (turbulent SST) 


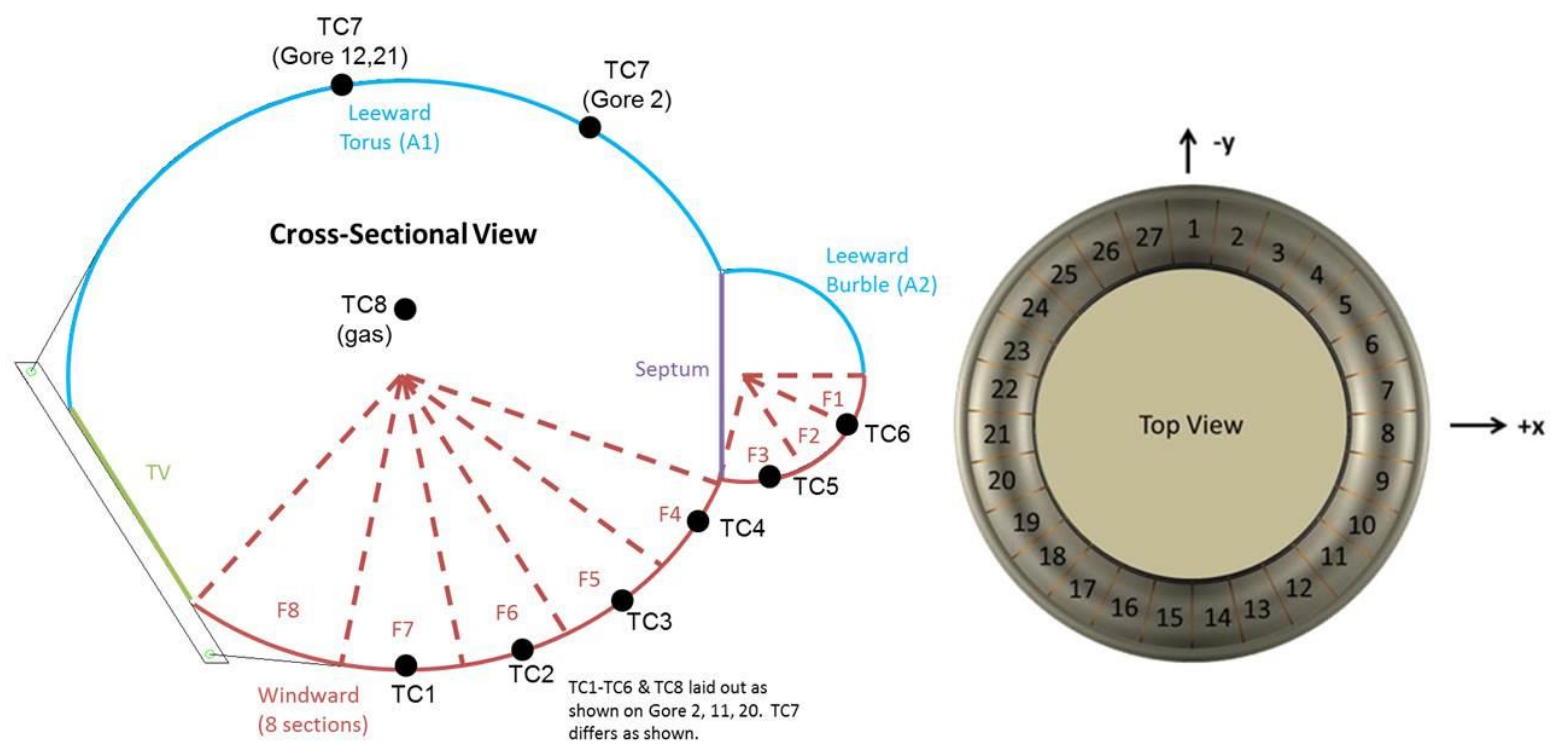

Figure 22. SIAD-R model sections and flight thermocouple layout. (24 thermocouples are arranged in three radial lines $120^{\circ}$ apart on gores 2,11 , and 20 )

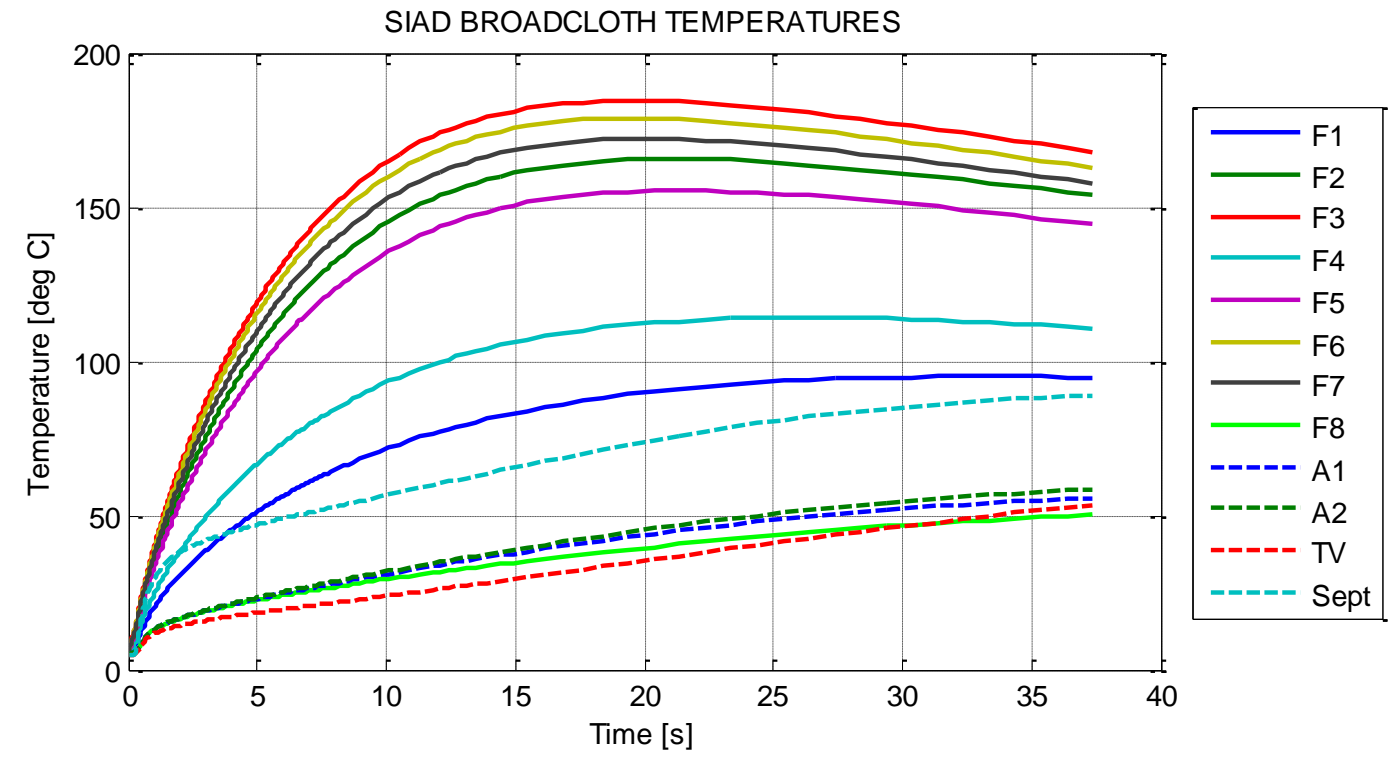

Figure 23. Fabric temperatures predicted by the response model for nominal pre-flight SFDT-1 trajectory. The lines correspond to the SIAD-R segments shown in Fig. 18. (Time = 0 sec corresponds to start of SIAD-R inflation.) 

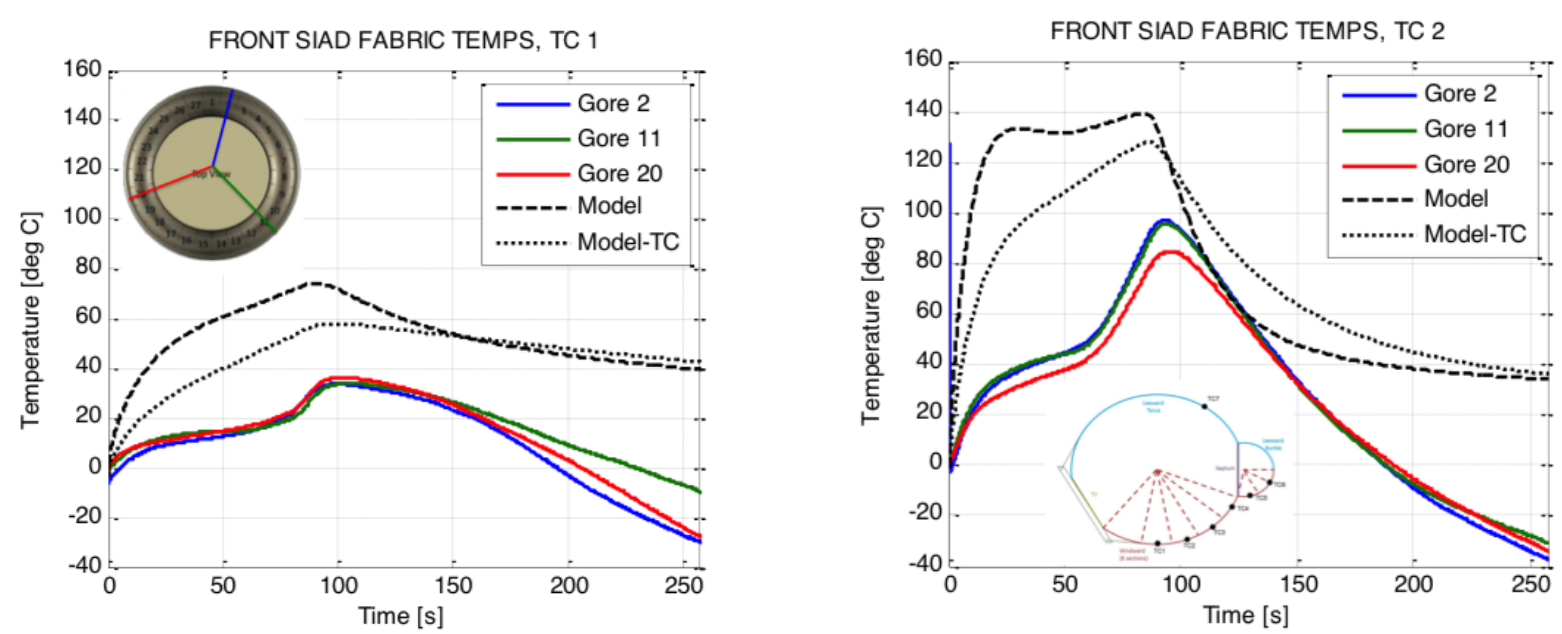

Figure 24. Thermocouple traces from TC1 and TC2 are compared to the thermal response model output. "Model-TC" indicates the predicted TC temperature and "Model" indicates the predicted SIAD-R fabric temperature.

\section{Conclusion}

Aerodynamic and aerothermal CFD simulations on a Supersonic Inflatable Aerodynamic Decelerator are outlined in this paper. Pre-flight simulations of the SIAD-R showed that the aftbody geometry and nonaxisymmetric shapes have minor influences on the overall aerodynamics of the test vehicle at supersonic cruise conditions. CFD simulations using idealized, axisymmetric approximations of the SIAD-R and actual laser-scanned geometries indicate that the maximum discrepancies in lift, drag, and pitch moment coefficients are less than $3 \%$. Based on these results, no corrections were made to an aerodynamic database generated using axisymmetric CFD solutions. Instead, differences due to non-axisymmetric shapes and aftbody geometry are factored into the aerodynamic uncertainty models, with uncertainties on the order of $\pm 10 \%$ for $C_{A}, C_{N}$ and $\pm 20 \%$ for $C_{m}$.

The aerodynamic database is validated by two sets of test data: 1) ballistic range test data from HFFAF and 2) flight data from SFDT-1. Comparisons between the HFFAF test data and CFD solutions shows excellent agreement in the lift and drag coefficients at small $\alpha$ 's. At higher angles of attack, differences in the lift coefficients are around $10 \%$ and future investigations are underway to study these differences. The successful flight test of SFDT-1 produced important data to validate our computer models. Comparison of the axial force coefficient between the aerodynamic database and flight data shows excellent agreement (maximum differences of $\sim 3 \%$ ). Normal force coefficients and pitching moment coefficients are also in very good agreement with flight data, although they could only be validated for small angles of attack. The temperature data from thermocouple measurements on the SIAD surface are also in reasonable agreement with the aerothermal response models (highest over-prediction of $\sim 35^{\circ} \mathrm{C}$ ), and has demonstrated that the thermal models are conservative. Model validation performed using SFDT-1 flight data has significantly advanced our capability to predict decelerator performance, and is paving the way for an analytical framework necessary for infusion of this technology in a future planetary mission.

\section{Acknowledgments}

The authors wish to thank Louis Giersch and Gabriel Molina at JPL for providing the CAD files and geometry information for SIAD-R. The authors are also thankful to Dan Coatta at JPL for the test data from the SIAD Design Verification (SDV) test and to Eric Blood of JPL for providing the flight data. 


\section{References}

${ }^{1}$ Clark, I. G., Adler, M., and Rivellini, T. "Development and Testing of a New Family of Low-Density Supersonic Decelerators”, AIAA Aerodynamic Decelerator Systems (ADS) Conference, Daytona Beach, FL, 2013, AIAA Paper 2013-1252

${ }^{2}$ Giersch, L., Rivellini, T., Clark, I., Shook, L., Ware, J., and Welch, J. "SIAD-R: A Supersonic Inflatable Aerodynamic Decelerator for Robotic missions to Mars", AIAA Aerodynamic Decelerator Systems (ADS) Conference, Daytona Beach, FL, 2013, AIAA Paper 2013-1327

${ }^{3}$ Wright, M. J., Candler, G. V., and Bose, D., "Data-Parallel Line Relaxation Method for the Navier-Stokes Equations," AIAA Journal, Vol. 36, No. 9, 1998.

${ }^{4}$ Brown, J. L., "Turbulence Model Validation for Hypersonic Flows," AIAA Paper 2002-3308, St. Louis, MO.

${ }^{5}$ Commercial grid generation software by Pointwise, Fort Worth, TX.

${ }^{6}$ Schoenenberger, M., Cheatwood, M., and Desai, P., "Static Aerodynamics of the Mars Exploration Rover Entry Capsule," AIAA Paper 2005-56, Reno, NV.

${ }^{7}$ Yates, L. A., "A Comprehensive Automated Aerodynamic Reduction System for Ballistic Ranges," Wright Laboratory, Armament Directorate, WL-TR-95-7059, Oct. 1996.

${ }^{8}$ Chapman, G. T., and Kirk, D. B., "A Method of Extracting Aerodynamic Coefficients from Free-Flight Data," AIAA Journal, Vol. 8, No. 4, April 1970.

${ }^{9}$ Aerodynamic Coefficients from Aeroballistic Range Testing of Deployed and Stowed-SIAD SFDT Models Final Report by NASA Ames Research Center and AerospaceComputing, Inc.

${ }^{10}$ Van Norman, J., Dyakonov, A., Schoenenberger, M., Davis, J., Muppidi, S., Tang, C., Bose, D., Mobley, B., and Clark, I., "Aerodynamic Models for the Low Density Supersonic Decelerator (LDSD) Supersonic Flight Dyanmics Test (SFDT)," AIAA Paper 2015, Daytona, FL.

${ }^{11}$ Muppidi, S., Tanimoto, R., Bose, D., Tang, C., and Clark, I., "Aerothermal Environment and Thermal Response of Supersonic Inflatable Decelerators”, AIAA SciTech Conference, Kissimmee, FL, 2015, AIAA Paper 2015-0208.

${ }^{12}$ Muppidi, S., Tang, C., Van Norman, J., Bose, D., Clark, I., and Coatta, D., "Aerodynamic Analysis of Next-Generation Supersonic Decelerators”, $32^{\text {nd }}$ AIAA Applied Aerodynamics Conference, Atlanta, GA, 2014, AIAA Paper 2014-2990. 